\title{
3D COMSOL Simulations for Thermal Deflection of HFIR Fuel Plate in the "Cheverton-Kelley" Experiments
}

June 2012

Prepared by

Prashant K. Jain James D. Freels David H. Cook
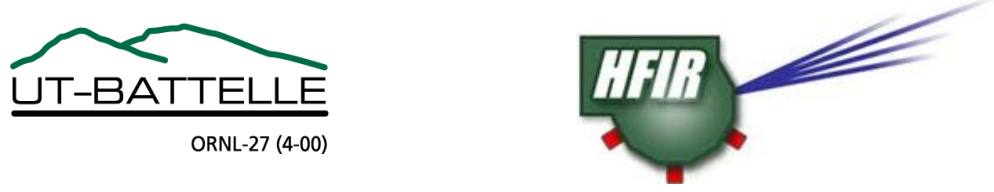


\title{
DOCUMENT AVAILABILITY
}

Reports produced after January 1, 1996, are generally available free via the U.S. Department of Energy (DOE) Information Bridge.

Web site http://www.osti.gov/bridge

Reports produced before January 1, 1996, may be purchased by members of the public from the following source.

\author{
National Technical Information Service \\ 5285 Port Royal Road \\ Springfield, VA 22161 \\ Telephone 703-605-6000 (1-800-553-6847) \\ TDD 703-487-4639 \\ Fax 703-605-6900 \\ E-mail info@ntis.gov \\ Web site http://www.ntis.gov/support/ordernowabout.htm
}

Reports are available to DOE employees, DOE contractors, Energy Technology Data Exchange (ETDE) representatives, and International Nuclear Information System (INIS) representatives from the following source.

Office of Scientific and Technical Information

P.O. Box 62

Oak Ridge, TN 37831

Telephone 865-576-8401

Fax 865-576-5728

E-mail reports@osti.gov

Web site http://www.osti.gov/contact.html

This report was prepared as an account of work sponsored by an agency of the United States Government. Neither the United States Government nor any agency thereof, nor any of their employees, makes any warranty, express or implied, or assumes any legal liability or responsibility for the accuracy, completeness, or usefulness of any information, apparatus, product, or process disclosed, or represents that its use would not infringe privately owned rights. Reference herein to any specific commercial product, process, or service by trade name, trademark, manufacturer, or otherwise, does not necessarily constitute or imply its endorsement, recommendation, or favoring by the United States Government or any agency thereof. The views and opinions of authors expressed herein do not necessarily state or reflect those of the United States Government or any agency thereof. 


\title{
3D COMSOL SIMULATIONS FOR THERMAL DEFLECTION OF HFIR FUEL PLATE IN THE “CHEVERTON-KELLEY” EXPERIMENTS
}

\author{
Prashant K. Jain \\ James D. Freels \\ David H. Cook
}

Date Published: June 2012

\author{
Prepared by \\ OAK RIDGE NATIONAL LABORATORY \\ Oak Ridge, Tennessee 37831-6283 \\ managed by \\ UT-BATTELLE, LLC \\ for the \\ U.S. DEPARTMENT OF ENERGY \\ under contract DE-AC05-00OR22725
}




\section{CONTENTS}

Page

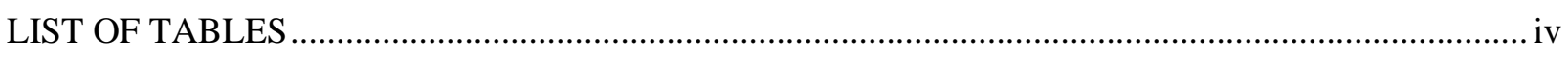

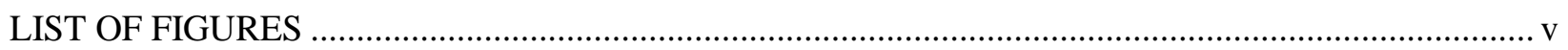

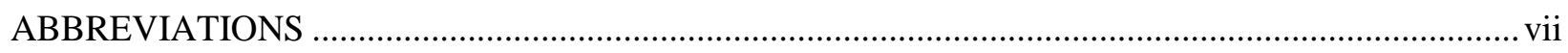

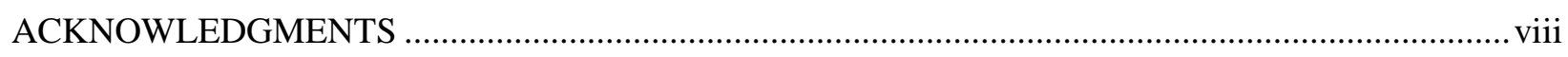

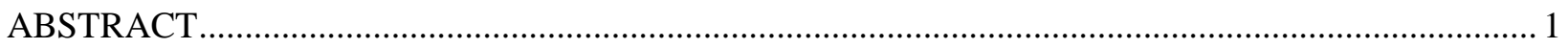

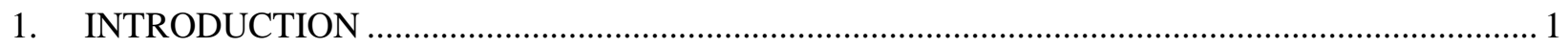

2. IMPORTANCE OF PREDICTING TEMPERATURE-INDUCED STRUCTURAL

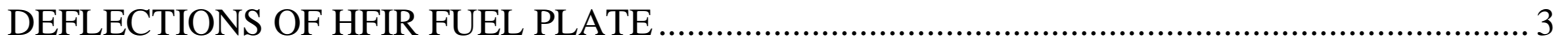

3. SUMMARY OF PAST EXPERIMENTAL INVESTIGATIONS BY CHEVERTON

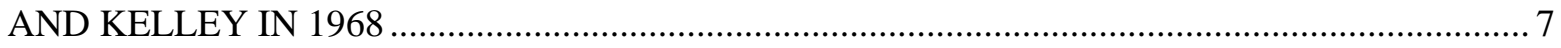

4. PRIMARY FINDINGS FROM THE CHEVERTON-KELLEY EXPERIMENTS ......................... 11

5. COMSOL SIMULATIONS OF THE CHEVERTON-KELLEY EXPERIMENTS ....................... 14

5.1 SIMULATION OF SINGLE PLATE WITH CONSTRAINED SIDE EDGES ....................... 14

5.1.1 OUTER TEST PLATE MADE OF ALUMINUM ................................................. 14

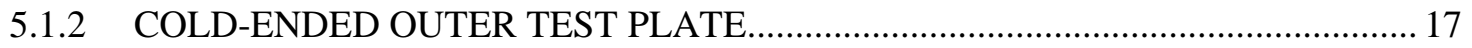

5.2 SIMULATION OF TEST PLATE ATTACHED TO A BASE .......................................... 19

5.2.1 ALUMINUM PLATE WITH SOLID/SPLIT STEEL AND INVAR BASES ........... 21

5.2.2 COLD-ENDED ALUMINUM PLATE WITH SOLID/SPLIT INVAR BASE .......... 24

6. COMPARISON OF SIMULATION RESULTS WITH EXPERIMENTAL DATA FOR

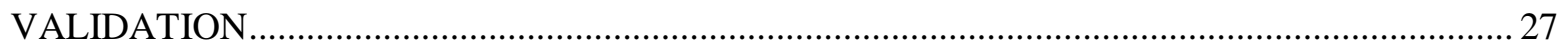

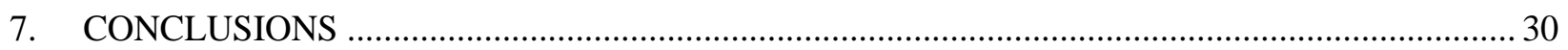

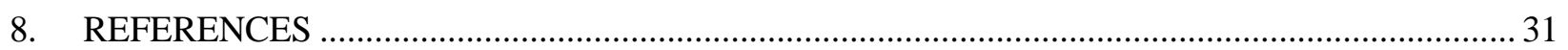




\section{LIST OF TABLES}

\section{Table}

Page

Table 1. Five U.S. high-performance research reactors in line for conversion to low enriched uranium fuel.

Table 2. A comparison of thermophysical properties of different base and plate materials at room temperature.

Table 3. Comparison of peak deformations at the longitudinal midspan and top/bottom ends of the plate with experimental data..... 


\section{LIST OF FIGURES}

Figure $\quad$ Page

Fig. 1. A dimensional sketch of HFIR fuel assembly and its cross-sectional plane............................ 3

Fig. 2. Several photographs of a mock HFIR fuel element showing geometrical complexity

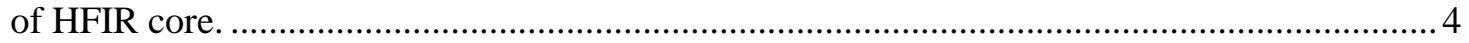

Fig. 3. Experimental setup designed and used by Cheverton and Kelley [19] to measure temperature-induced structural deflections of a HFIR fuel plate ............................................ 9

Fig. 4. Different components of the experimental thermal deflection measurement apparatus............ 9

Fig. 5. A dimensional comparison (in inches) of the HFIR outer fuel plate and the test plate used in the Cheverton-Kelley experiments.

Fig. 6. (a) Seven styluses (numbered) of the differential transformer units are shown mounted on the bridge that travels on the track's guideways. ....

Fig. 7. Experimental results for a fuel plate on a split steel base constrained at its longitudinal edges through 0.25 in. tab attachments (the negative deflections at the top and bottom ends are due to the split base).

Fig. 8. Experimentally measured transverse deflections (across the plate's radial width) for the outer HFIR fuel plate attached to an Invar base.

Fig. 9. (a) Cross-sectional face of the involute plate sketched on a 2D work-plane in COMSOL Multiphysics. (b) 2D involute surface is extruded in the $z$-direction to generate the outer test plate in 3D. Fixed constraints (all the displacements are restricted to be zero) are applied at both longitudinal edges of the plate. (c) A nonuniform mapped mesh is generated for the plate.

Fig. 10. (a) Deformation in the HFIR outer test plate due to thermal expansion caused by its convective heating from $80^{\circ} \mathrm{F}$ to $400^{\circ} \mathrm{F}$. (b) Fuel plate deflections at the bottom end ( $z=0$ in.) and mid-span $(z=12$ in.) of the plate.

Fig. 11. Temperature-induced deflections - with no viewgraph scaling — at different cross sections of HFIR's outer test plate in the COMSOL Multiphysics simulation results.

Fig. 12. A plate's deflection in mil along its length at its longitudinal center plane (1.54 in. arc length from the left edge of the plate).

Fig. 13. (a) COMSOL Multiphysics model of HFIR's outer test plate with cold (steel) ends.

(b) A user-controllable mapped mesh is shown for the cold-ended plate.

Fig. 14. Deformation in the cold-ended outer test plate due to thermal expansion caused by convective heating from $80^{\circ} \mathrm{F}$ to $400^{\circ} \mathrm{F}$.

Fig. 15. Deflections at the bottom end $(z=0$ in.), cold end interface $(z=2$ in.) and at mid-span $(z=12$ in.) of the cold-ended outer test plate.

Fig. 16. Cold-ended plate's deflection along its length at its longitudinal center plane (1.54 in.

arc length from the left edge of the plate) (in mil).

Fig. 17. Drawing for the base geometry (dimensions in inches) used in the Cheverton-Kelley tests (source: drawing no. E50166)...

Fig. 18. CAD geometry and meshing developed for the simulation of differential thermal expansion in Cheverton-Kelley experiments.

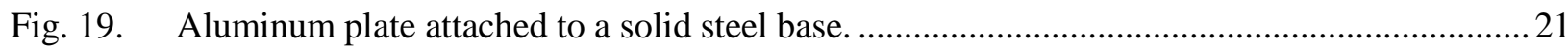

Fig. 20. Aluminum plate attached to a split steel base ................................................................22

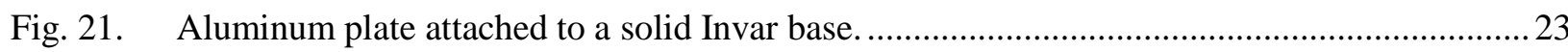


Fig. 22. Aluminum plate attached to a split Invar base ..................................................................24

Fig. 23. Cold-ended aluminum plate attached to a solid Invar base...................................................25

Fig. 24. Cold-ended aluminum plate attached to a split Invar base. ..................................................26

Fig. 25. Comparison of mid-span deflections of an aluminum plate attached with Invar (a) solid and (b) split bases with experimental results in Fig. 8.

Fig. 26. Comparison of mid-span and longitudinal deflections of an aluminum plate attached with split steel base with experimental results in Fig. 7. 


\section{ABBREVIATIONS}

2D

$3 \mathrm{D}$

$\mathrm{CAD}$

DOE

GTRI

HEU

HFIR

HPRR

LEU

NRC

ORNL

RERTR

SSHTC

TSI two dimensional

three dimensional

computer-aided design

U.S. Department of Energy

Global Threat Reduction Initiative

highly enriched uranium

High Flux Isotope Reactor

High performance research reactor

low enriched uranium

Nuclear Regulatory Commission

Oak Ridge National Laboratory

Reduced Enrichment for Research and Test Reactors

Steady State Heat Transfer Code

thermal structural interaction 


\section{ACKNOWLEDGMENTS}

The authors would like to acknowledge that the support for this project was provided by the Global Threat Reduction Initiative (GTRI), Reduced Enrichment for Research and Test Reactors program (RERTR), Nuclear National Security Administration, U.S. Department of Energy (DOE). The DOE program manager was Christopher C. Landers, the Argonne National Laboratory RERTR Reactor Conversion program manager was Dr. John Stevens, and the Fuel Fabrication Capability program manager was Dr. Douglas Burkes of the Pacific Northwest National Laboratory. The authors also acknowledge the technical review of this document performed by Mr. David G. Renfro and Dr. Kevin A. Smith, Research Reactors Division, Oak Ridge National Laboratory. 


\begin{abstract}
Three dimensional simulation capabilities are currently being developed at Oak Ridge National Laboratory using COMSOL Multiphysics, a finite element modeling software, to investigate thermal expansion of the High Flux Isotope Reactor (HFIR) low enriched uranium fuel plates. To validate simulations, 3D models have also been developed for the experimental setup used by Cheverton and Kelley in 1968 to investigate the buckling and thermal deflections of HFIR's highly enriched uranium fuel plates. Results for several simulations are presented in this report, and comparisons with the experimental data are provided when data are available. A close agreement between the simulation results and experimental findings demonstrates that the COMSOL simulations are able to capture the thermal expansion physics accurately and that COMSOL could be deployed as a predictive tool for more advanced computations at realistic HFIR conditions to study temperature-induced fuel plate deflection behavior.
\end{abstract}

\title{
1. INTRODUCTION
}

The primary mission of the Global Threat Reduction Initiative (GTRI) [1]—a program of the U.S. Department of Energy (DOE) National Nuclear Security Administration - is to reduce and protect vulnerable nuclear and radiological materials located at civilian sites worldwide. Under one of the GTRI's subprograms, the Reduced Enrichment for Research and Test Reactors (RERTR) [2], research reactors and isotope production facilities around the world are being converted from their use of highly enriched uranium (HEU) fuel to low enriched uranium (LEU) fuel. To date, 80 of 129 such reactors have been converted or shut down worldwide, resulting in a significant reduction of the use of and need for HEU in civilian applications. This includes 23 conversions (16 international and 7 in the United States) since 2004. All of the U.S. research reactors that can be converted with the existing LEU fuel (uranium silicide, $\mathrm{U}_{3} \mathrm{Si}_{2}$ fuel) have already been converted. Seven U.S. research reactors that have recently been converted are from:

Texas A\&M University (2006),

University of Florida (2006),

Purdue University (2007),

Oregon State University (2008),

Washington State University (2008),

Idaho National Laboratory (2009), and

University of Wisconsin (2009).

Five U.S. high-performance research reactors (HPRRs) still need to be converted to LEU fuel (see Table 1); however, using our present silicide-based LEU fuel will not yield the same level of performance for those reactors, and therefore options for an ultrahigh-density LEU fuel are currently being explored. High-density LEU fuel should be able to withstand high to very high heat fluxes (fission rates) and high burn-ups (fission density). Two very high-density LEU fuels are currently being developed by the GTRI conversion program: U-Mo dispersion fuel ( $\mathrm{U}$ density limit $\sim 8.5 \mathrm{~g} / \mathrm{cc}$ ) and $\mathrm{U}-\mathrm{Mo}$ monolithic fuel ( $\mathrm{U}$ density limit $\sim 17 \mathrm{~g} / \mathrm{cc}$ ); the latter is the most suitable for HPRR conversions [3-5]. 
Table 1. Five U.S. high-performance research reactors in line for conversion to low enriched uranium fuel ${ }^{a}$

\begin{tabular}{lccc}
\hline \multicolumn{1}{c}{ Reactor } & $\begin{array}{c}\text { HEU core } \\
\text { power (MW) }\end{array}$ & Primary use & Regulator $^{b}$ \\
\hline $\begin{array}{l}\text { Massachusetts Institute of Technology Nuclear } \\
\text { Reactor }\end{array}$ & 5 & Mixed & NRC \\
University of Missouri Research Reactor & 10 & Activation, isotope production & NRC \\
$\begin{array}{l}\text { National Bureau of Standards Reactor (NBSR) } \\
\text { Advanced Test Reactor (ATR) }\end{array}$ & 20 & Beam science & NRC \\
High Flux Isotope Reactor & $100-250$ & Fuel and material irradiation & DOE \\
& 85 & $\begin{array}{c}\text { Beam science, isotope } \\
\text { production, fuel and material } \\
\text { irradiation }\end{array}$ & DOE \\
\hline
\end{tabular}

${ }^{a}$ Source: Adapted from J. G. Stevens, "Technical Challenges for Conversion of U.S. High Performance Research Reactors," Presentation to NAS/RAS committee on conversion of research reactors available at: http://dels.nas.edu/resources/staticassets/nrsb/miscellaneous/StevensPresentation.pdf, 2010.

${ }^{b}$ U.S. Department of Energy (DOE); Nuclear Regulatory Commission (NRC).

Extensive research and development is currently under way at the Oak Ridge National Laboratory (ORNL) High Flux Isotope Reactor (HFIR) to convert it from its present HEU fuel core to an LEU fuel core [6-16]. Because HFIR is the highest-flux reactor-based neutron source for condensed matter research in the United States, its conversion to an LEU fuel should not impact its current neutron flux performance. Furthermore, cost, budgetary, and availability issues have dictated that minimal changes be made to the overall HFIR facility. Therefore, the goal is to only substitute the fuel type in the existing fuel plate design, retaining the same number of fuel plates, with the same physical dimensions, as in the current HFIR core.

HFIR was designed and constructed in the mid-1960s. At that time, its thermal safety analyses were based on an in-house code named the "Steady State Heat Transfer Code" (SSHTC) [17]. The SSHTC used results from several experiments and validation exercises performed with HEU fuel plates during HFIR's original design stages. It is still in use at HFIR and has changed very little since its original development. However, several of its empirical correlations may not be applicable to a U-Mo LEU fuel core, and in the absence of an extensive experimental effort to revalidate SSHTC for the LEU fuel design, the focus now is on adopting the best available multiphysics simulation technology to answer the needs of the conversion process. COMSOL Multiphysics, a commercial finite-element-method-based modeling and simulation software, [18], has been identified to support these needs and to eventually replace SSHTC.

In SSHTC, thermal structural interaction (TSI) physics is incorporated via empirical correlations derived from the experimental thermal deflection data produced by Cheverton and Kelley in 1968 [19] (called the "Cheverton-Kelley" tests). The correlations were developed for the HEU fuel plate in a convectively heated environment and may not be directly applicable for the U-Mo LEU plate. To assess the need for redesigning, rebuilding, and repeating the Cheverton-Kelley tests for the LEU fuel plate, three-

dimensional (3D) COMSOL simulations were first performed for the selected experiments that involved the aluminum test plate. Simulation results showed a reasonable agreement with the test data and demonstrated COMSOL's ability to accurately capture the temperature-induced deflections observed in the Cheverton-Kelley tests. In addition to validating COMSOL for TSI physics, the simulation results also confirmed that duplication of the Cheverton-Kelley tests would not be required for TSI analyses of LEU fuel plates. 


\section{IMPORTANCE OF PREDICTING TEMPERATURE-INDUCED STRUCTURAL DEFLECTIONS OF HFIR FUEL PLATE}

HFIR is one of the highest neutron flux producing research reactors in the world. It was designed and built in the early 1960s and has been in operation since then. HFIR is a compact flux-trap reactor with a very-high-power-density fuel core (e.g., for operation at $100 \mathrm{MW}$, HFIR's power density is $2 \mathrm{GW} / \mathrm{m}^{3}$ ). As shown in Figs. 1 and 2, HFIR's 50 L core consists of two 24 in. tall cylindrical fuel elements (called the inner and outer fuel elements) built from 540 uniformly spaced thin involute-shape aluminum fuel plates (171 inner and 369 outer plates). The inner and outer fuel plates are of the same thickness $(50 \mathrm{mil}, 1 \mathrm{mil}=$ 0.001 in.) and height ( $2 \mathrm{ft})$; however, they slightly differ in their radial width ( $\sim 3 \mathrm{in}$.) and radial fuel distribution contours. The involute of the outer fuel plate is relatively flatter than that of the inner fuel plate because of the larger radius of its base circle of involute. HFIR plates have a radially contoured fuel meat distribution with reduced fuel density (by decreasing thickness of meat) near each plate's side edges to minimize radial power peaking caused by a water (moderator) gap in the side plates.

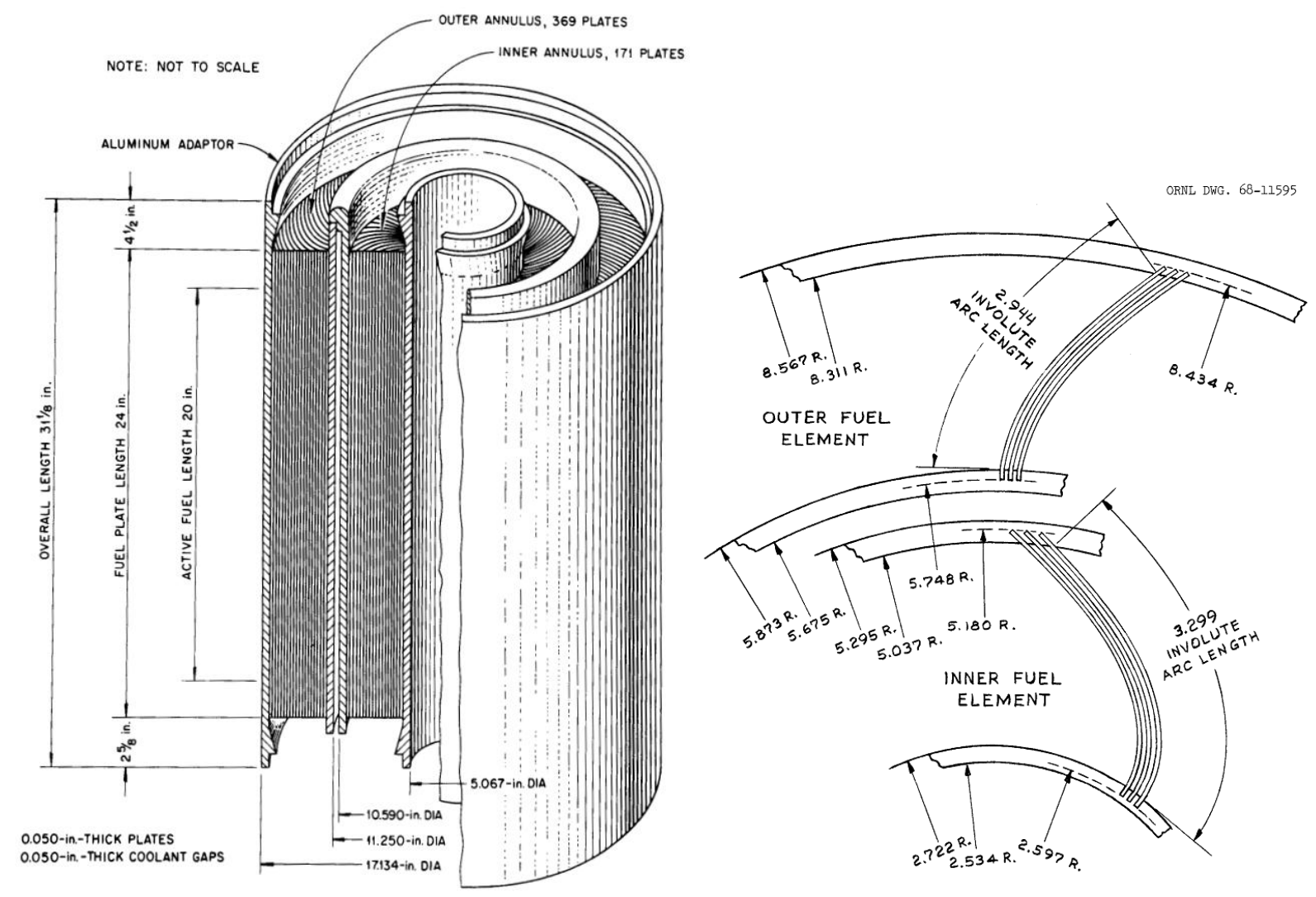

Fig. 1. A dimensional sketch of HFIR fuel assembly and its cross-sectional plane. 

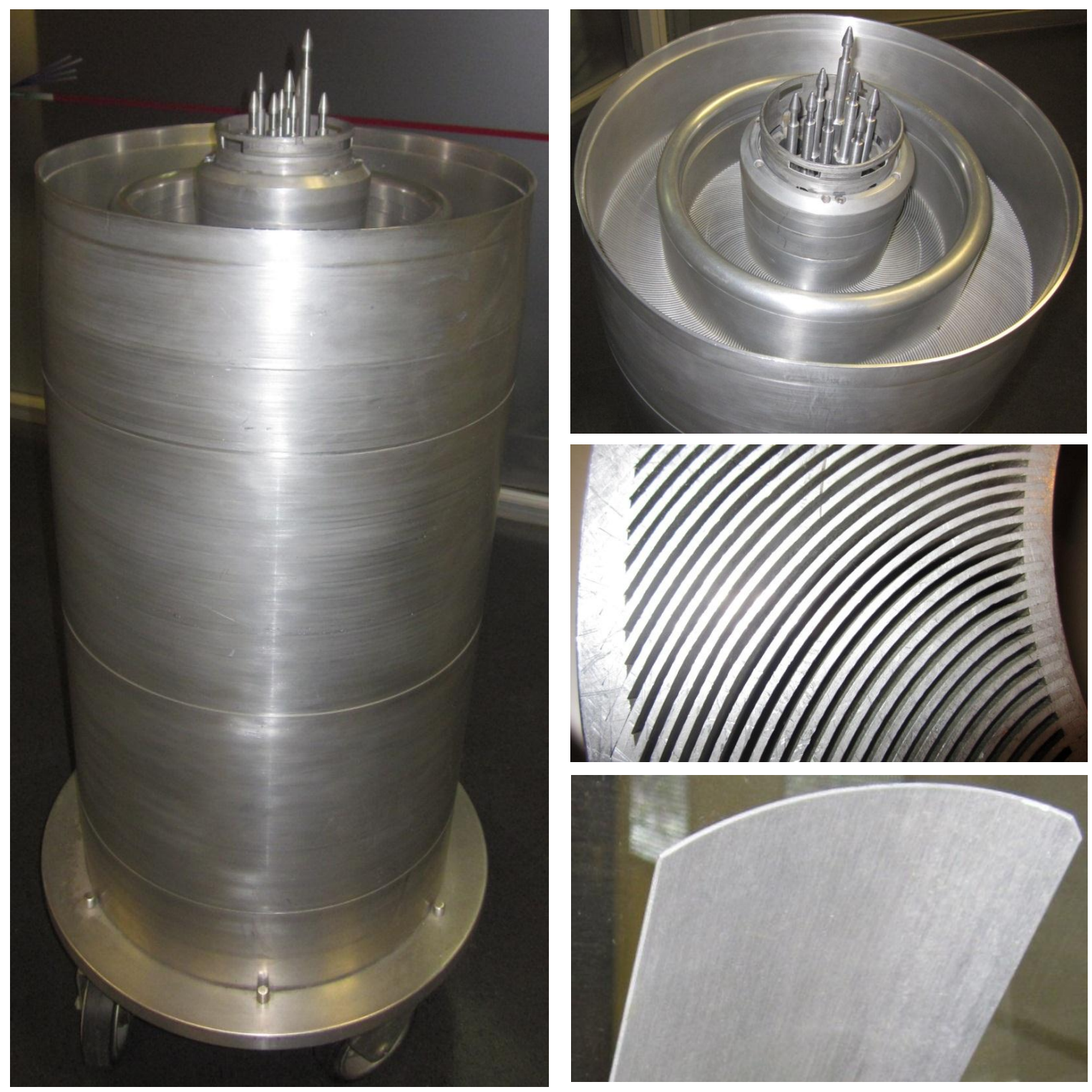

Fig. 2. Several photographs of a mock HFIR fuel element showing geometrical complexity of HFIR core.

The involute-shaped fuel plates in HFIR are uniformly spaced so as to provide an equal coolant flow area for each plate within each element. To remove the heat generated in the fuel plates, light water coolant is forced through the gaps between the plates at an average inlet velocity of $15.8 \mathrm{~m} / \mathrm{s}$. A total of $13,000 \mathrm{gal}$ of water passes through the HFIR core every minute. Even then there is a possibility of developing unwanted hot regions within the HFIR fuel elements $[17,19,20]$ for the following reasons:

manufacturing tolerances in fuel plate dimensions,

thermal expansion of plates due to radially and axially varying time-dependent heat generation rates, possible local segregation of fuel and nonbonds with cladding,

extension of fuel-bearing material beyond its nominal boundaries,

pressure- and turbulence-induced structural deflections,

buildup of oxide layers on the plate surfaces, etc. 
Thus a reasonably accurate prediction of the hot regions becomes necessary to ensure the safety of the reactor when it is converted to use LEU fuel.

In the core region, HFIR's thermal performance requirements are very close to their operational limits. Thermal safety margins are especially lower in the bottom few inches of the core because of the reduced heat transfer between fuel plates and the downward flowing coolant, which, by the time it reaches the lower part of the core, is at a higher temperature, resulting in a lower temperature differential between the clad surface and the coolant. In addition, a lower coolant pressure in the bottom region of the core further reduces the margin between the clad surface temperature and the saturation temperature corresponding to the local pressure. Unwanted incipient boiling (void generation and its subsequent feedback to neutronics) could lead to hot-spot burnouts and/or subsequent flow instabilities/excursions [20]. Many physical processes - including turbulent coolant flow, conjugate heat transfer, thermal-expansion-induced structural deflections (thermal structural interaction), and deflections due to a pressure differential across a fuel plate (fluid-structure interaction) — can play significant roles in dictating the HFIR core's overall thermal safety limits.

In HFIR's fuel elements, both the inner and outer longitudinal edges of each fuel plate are attached to an inner and outer cylindrical side plate (see Fig. 1) through tightly fitting in grooves and welding at 1 in. intervals (the welds being 0.12 in. long). Because of (i) absence of direct heat source (from fuel) in side plates other than gamma absorption and (ii) additional coolant flow through its gaps, the aluminum side plates stay significantly cooler than the fuel plates and therefore undergo a lower thermal expansion than the fuel plates. That, along with the nonuniform heat generation in the fuel plates (with top and bottom peaks), gives rise to a nonuniform thermal expansion of the fuel plates relative to the cooler side plates (differential thermal expansion).

In an ideal case, where each plate in the HFIR fuel elements was identical to the other, and where there were no mechanical (channel thickness, fuel loading or fuel homogeneity) or operational perturbations, we could have a scenario where azimuthally symmetric neutron flux distribution would produce a uniform deflection pattern for each plate. Each plate would bow in the same direction by the same amount and would have no significant impact on the thickness of the adjacent coolant channels. However, such idealism is not possible in engineering practice, and one has to allow for off-nominal fuel distributions and mechanical tolerances within a controlled range. Such perturbations, along with the nonuniform heat sources in the plates (in axial, radial, and azimuthal directions), could cause partial closure or significant narrowing of the coolant channels due to possible unequal deflections of adjacent plates and may lead to safety issues. Therefore, it is necessary to assess a plate's maximum thermal deflection after conservatively accounting for various perturbations.

In addition, if the temperature difference between a fuel plate and a side plate becomes large enough, and if the subsequent longitudinal thermal stresses in a plate exceed a critical value, the fuel plate may buckle during operation. The critical buckling stress depends upon several system parameters, including plate temperature (material properties), initial geometry, the means of edge attachments to side plates, and temperature distribution in both the fuel plate and the side plate. Due to this possibility, in 1968 Cheverton and Kelley experimentally investigated [19] the differential thermal expansion of a HFIR fuel plate with a viewpoint that it could buckle under HFIR operating conditions. However, buckling was never observed in their tests and has not occurred at any time during HFIR's long history of operation. In addition, several separate-effect experiments conducted for Idaho's Advanced Test Reactor development during the same time indicated that the buckling stress would not be achieved for HFIR plates under its operating conditions. Considering that in LEU plates, only the fuel meat is being replaced with approximately same contour shape as the HEU plates, buckling may not be an issue if the steady state temperatures in the LEU fuel plates would be in the same range as in their HEU counterparts. 
Furthermore, because U-Mo fuel material is going to be inherently stiffer than the HEU, it would be less prone to buckling when subjected to the same conditions as the HEU fuel. 


\section{SUMMARY OF PAST EXPERIMENTAL INVESTIGATIONS BY CHEVERTON AND KELLEY IN 1968}

To investigate the possibility of buckling in HFIR fuel plates, Cheverton and Kelley designed an experiment [19] in 1968 to generate thermal stresses in a HFIR fuel plate and measure its differential thermal expansion (see Figs. 3 through 6). In their experiments, an involute shaped HFIR test plate attached to a base was slowly brought to a uniform temperature in an oven (i.e., it underwent convective heating), and temperatureinduced deflections were measured. Involute shape of the outer fuel plate was chosen for the experimental test plates to provide conservative measures because the outer plate is relatively flatter than the inner plate and therefore is more prone to longitudinal buckling. The base material was chosen to have a lower coefficient of thermal expansion than the fuel plate to allow differential thermal expansion of the fuel plate. By choosing different base materials (different thermal expansion coefficients), a family of curves in the plate's longitudinal (axial or along the length of the plate) and transverse (radial or along the width of the plate) directions were obtained to quantify the effects of different side plate materials on the fuel plate deflections at different temperatures of the fuel plate. Thermal deflection data were collected

- at several temperatures (ranging from $100^{\circ} \mathrm{F}$ to $400^{\circ} \mathrm{F}$ );

- for several base materials (carbon steel, Invar, and Monel);

- $\quad$ for different base types (solid base, split base — to mimic rotating side plates in HFIR);

- for different test plates (fuel plate, aluminum plate, aluminum plate with steel ends_- "cold-ended"); and

- for several different edge and end attachments (at different intervals and with different widths of attachments).

Note that Invar is a $36 \%$ nickel-iron alloy with a thermal expansion coefficient approximately one-tenth that of carbon steel up to $200^{\circ} \mathrm{C}$. Invar was chosen to increase the differential thermal expansion of the plate relative to the base and thus to provide conservative estimates of temperature-induced deflections of the HFIR plate. In contrast, Monel is a 63\% nickel-copper alloy with high strength and excellent corrosion resistance, and a thermal expansion coefficient very close to the carbon steel. In Table 2, several thermophysical properties of different base and plate materials at room temperature are compared.

Table 2. A comparison of thermophysical properties of different base and plate materials at room temperature $^{c}$

\begin{tabular}{lllllll}
\hline Material & $\begin{array}{l}\text { Coefficient of } \\
\text { thermal } \\
\text { expansion } \\
(\boldsymbol{\mu m} / \mathbf{m}-\mathbf{K})\end{array}$ & $\begin{array}{l}\text { Thermal } \\
\text { conductivity } \\
(\mathbf{W} / \mathbf{m}-\mathbf{K})\end{array}$ & $\begin{array}{l}\text { Density } \\
\left(\mathbf{k g} / \mathbf{m}^{\mathbf{3}}\right)\end{array}$ & $\begin{array}{l}\text { Specific heat } \\
\text { capacity } \\
(\mathbf{J} / \mathbf{k g}-\mathbf{K})\end{array}$ & $\begin{array}{l}\text { Modulus of } \\
\text { elasticity } \\
(\mathbf{G P a})\end{array}$ & $\begin{array}{l}\text { Poisson's } \\
\text { ratio }\end{array}$ \\
\hline Al-6061 & 23.6 & 167 & 2700 & 896 & 69 & 0.33 \\
Carbon steel & 12.9 & 47.4 & 7850 & 477 & 203 & 0.29 \\
Invar & 1.3 & 10.15 & 8050 & 515 & 141 & 0.3 \\
Monel & 13.9 & 21.8 & 8800 & 427 & 169 & 0.295 \\
\hline
\end{tabular}

${ }^{c}$ Source: Material property data from www.matweb.com. 
Figure 3 shows an involute-shape HFIR test plate constrained to a solid steel base through artificial tab attachments at regular intervals (to simulate intermittent weld attachments in a HFIR fuel element) on the plate's longitudinal sides. The plate is held in place on the base using two steel bars and several screws (see Fig. 4). Large screws hold the bars to the base, while smaller adjustment screws secure the tabs of the plate to the base. The base, which has proper involute edge angles machined on it, is mounted on a track that is used as a reference surface for deflection measurements. Plate deflections were measured by a differential transformer unit consisting of seven measurement styluses distributed across the width of the plate. The transformer unit is able to move in the longitudinal direction on the track's guideways to allow deflection measurements at different heights of the plate. In the experiments, test plates were convectively heated to uniform temperatures, unlike the actual HFIR core, where the plates are heated nonuniformly (in both the radial and longitudinal directions) from the inside.

Note that the HFIR fuel plates (both inner and outer) do not carry any fuel in the top and bottom 2 in. of its longitudinal ends, resulting in a significantly lower temperature in those regions (called the "cold-end" effect). Because the differential expansion between the side plates and fuel plate's cold ends remains small, the unfueled ends act as restraints at the ends of the fuel plate. In an attempt to get closer to the realistic HFIR conditions, some experiments were performed with cold ends where the top and bottom 2 in. of aluminum test plate were cut off and replaced with the same length involute end extensions taken from a mock steel test plate. The steel ends were attached to the test plate by means of $0.25 \mathrm{in}$. overlap epoxy-cemented joints. Steel was chosen for the cold ends because it has a lower thermal expansion coefficient than the aluminum, and therefore can mimic the effects of relatively cooler top and bottom 2 in. of HFIR fuel plates.

On the same experimental setup, Cheverton and Kelley also did some experiments to measure the pressure-induced deflections (separate effect tests) and combined pressure- and temperature-induced deflections (integral effects). Simulation of pressure-induced deflections in the Cheverton-Kelley setup is not part of this investigation and therefore was not modeled and is not discussed in this document. Efforts that are independent of this study are underway at ORNL to capture pressure-induced deflections through simulations of fluid-structure interactions of HFIR fuel plates. 


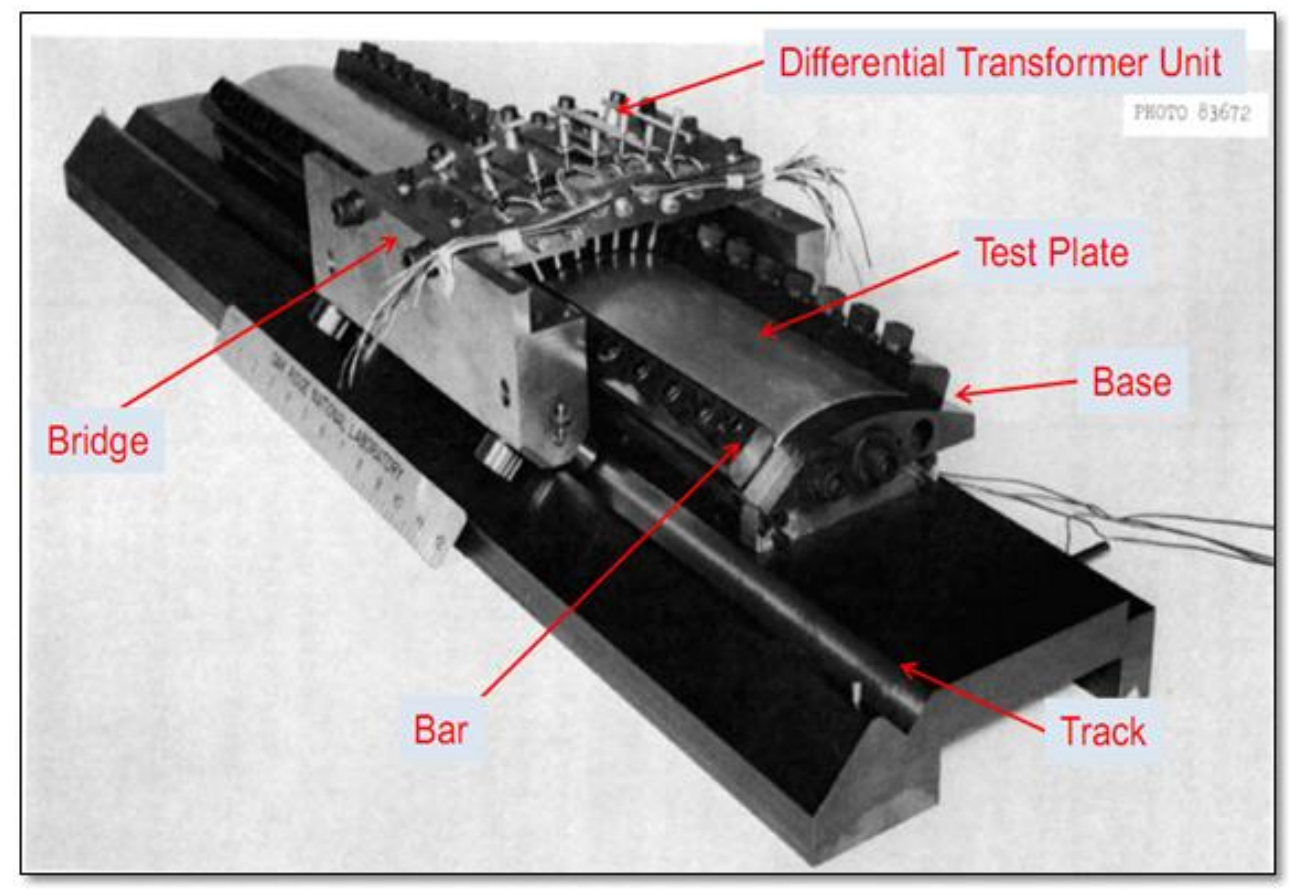

Fig. 3. Experimental setup designed and used by Cheverton and Kelley [19] to measure temperatureinduced structural deflections of a HFIR fuel plate.

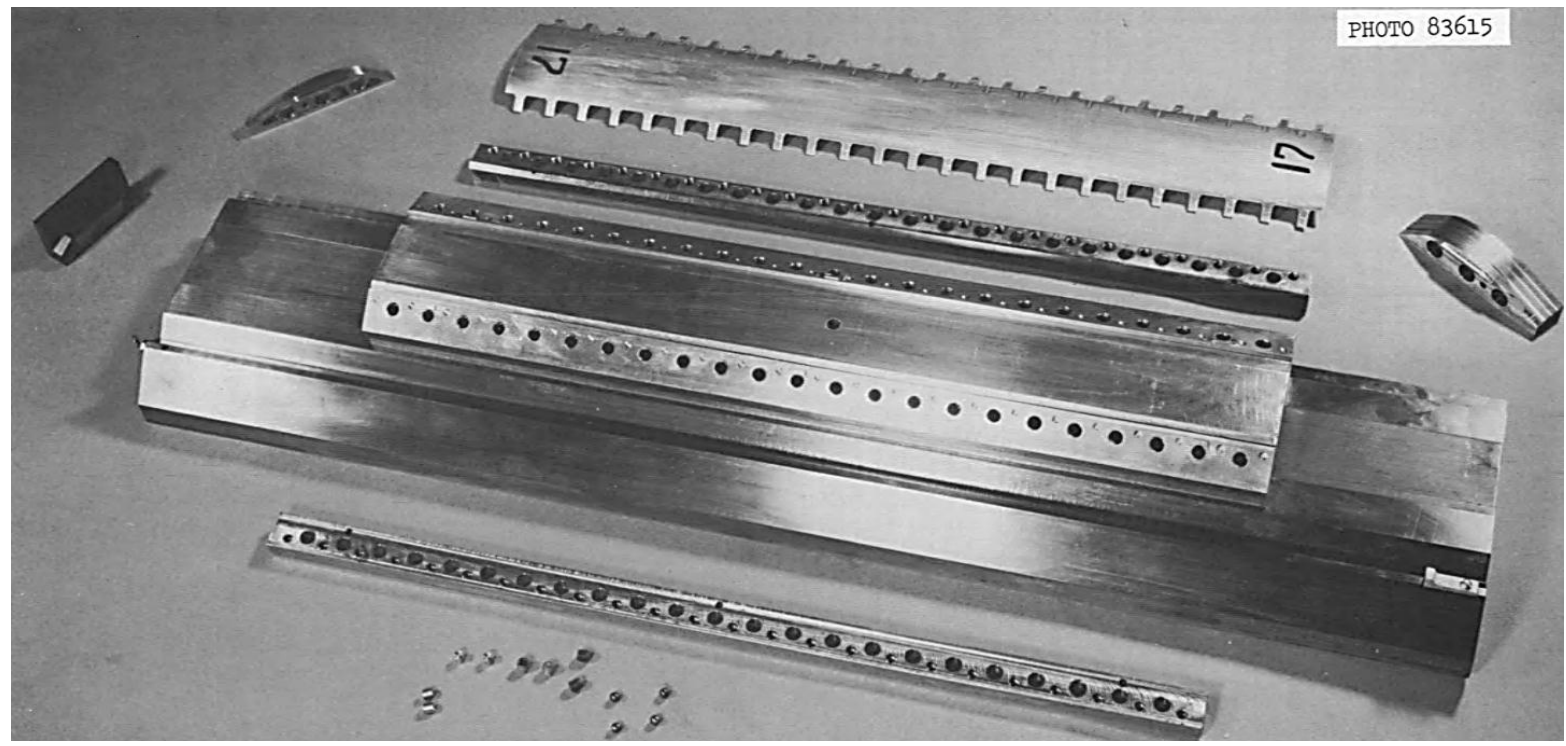

Fig. 4. Different components of the experimental thermal deflection measurement apparatus. Involute shape end blocks on the top left and right of this photograph are used to constrain the top and bottom ends of the fuel plate in some of the experiments [19]. 

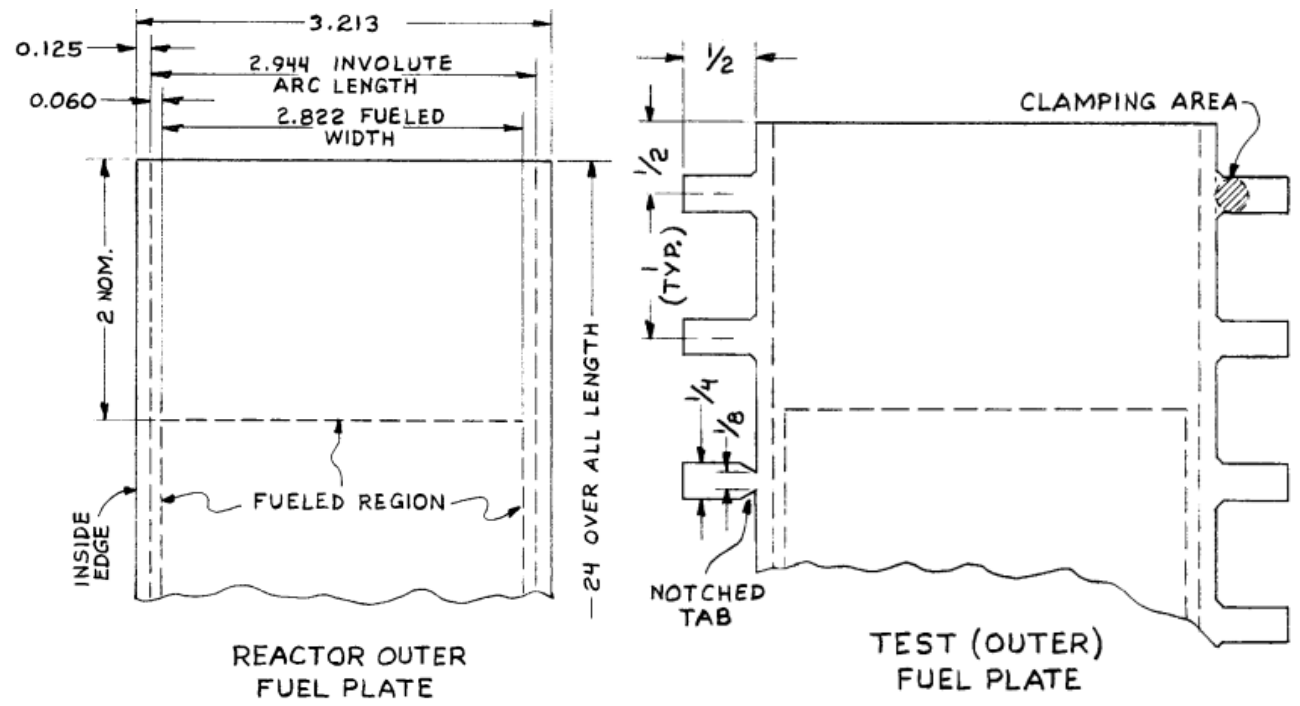

Fig. 5. A dimensional comparison (in inches) of the HFIR outer fuel plate and the test plate used in the Cheverton-Kelley experiments. The 2 in. long region in the top (and bottom, not shown here) portion of the fuel plate do not contain fuel. Tab attachments are shown on the longitudinal sides of the test plate. The test plate was clamped by bars and screws to remain tightly attached to the base [19].

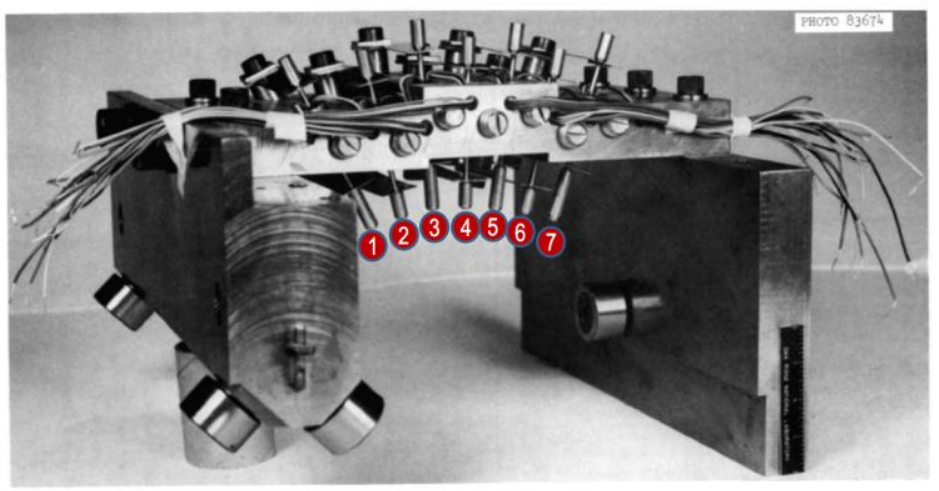

(a)

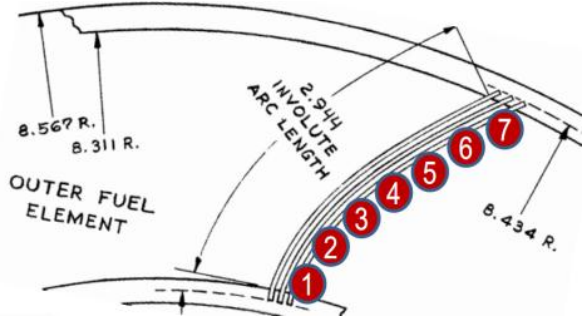

(b)

Fig. 6. (a) Seven styluses (numbered) of the differential transformer units are shown mounted on the bridge that travels on the track's guideways. Styluses are supported from the bridge and are lightly springloaded against the test plate by means of parallel leaf springs. Positioning is such that the axis of each stylus is always normal to the true involute curve at its point of contact with the plate surface. (b) Positions of contact are measured in arc length from the involute-generating circle (radius $=5.873 \mathrm{in}$.) of the outer plate: (1) 0.125 in., (2) 0.575 in., (3) 1.025 in., (4) 1.475 in., (5) 1.925 in., (6) 2.375 in., and (7) 2.825 in. [19]. 


\section{PRIMARY FINDINGS FROM THE CHEVERTON-KELLEY EXPERIMENTS}

The Cheverton-Kelley experiments indicated that (i) the central portion of the HFIR fuel plates would always deflect toward the convex side of the involute, (ii) close to its ends, the plate will deflect toward the concave side for a split base experiment (designed to mimic rotatable side plates in HFIR) and toward the convex side for a solid base. Typical plate deflections along the longitudinal direction and at several cross sections at different heights are shown in Fig. 7.

One of the test plates was subjected to a $600^{\circ} \mathrm{F}$ oven temperature-representing three times larger differential strain than for a plate at $400^{\circ} \mathrm{F}$ (typical of HFIR conditions). However, the plate did not buckle longitudinally (i.e., the critical buckling load was not achieved). Furthermore, above a temperature of $300^{\circ} \mathrm{F}$, the shape and deflection of the plate remained nearly constant.

Experiments to account for the effects of creep (retaining a maximum $400^{\circ} \mathrm{F}$ temperature for up to 15 days) and thermal cycling (up to four cycles between room temperature and $400^{\circ} \mathrm{F}$ ) indicated that they do not have a significant impact on HFIR's fuel plate deflections.

Experiments with solid and split bases resulted in deflections with the same shape in most of the plate; however, the magnitudes of deflections were almost two times larger for a plate attached to a solid base than a split base of the same material. Furthermore, top and bottom end deflections were found to be in the direction opposite to the convex curve of the involute for a split base. A comparison is shown in Fig. 8 for the outer fuel plate attached to a solid and a split Invar base.

Several types of edge restraints (different tab widths, fixing intervals, and methods of fixation) were used in the experiments. The deflection at the center of the plate tends to increase with an increasing degree of side edge restraint. Similar observations were made for the experiments with different degrees of end restraint on the top and bottom ends.

To identify the effects of a plate's initial shape on its deflections, experiments were conducted by purposely inducing perturbations in plate shape by alternate cup-and-ball force applicators on the edge tabs. Measured deflections were found to be very close to that of the regularly shaped plate. Therefore, it was concluded that the small perturbations in initial shape of the plate do not significantly affect the thermal deflections. 


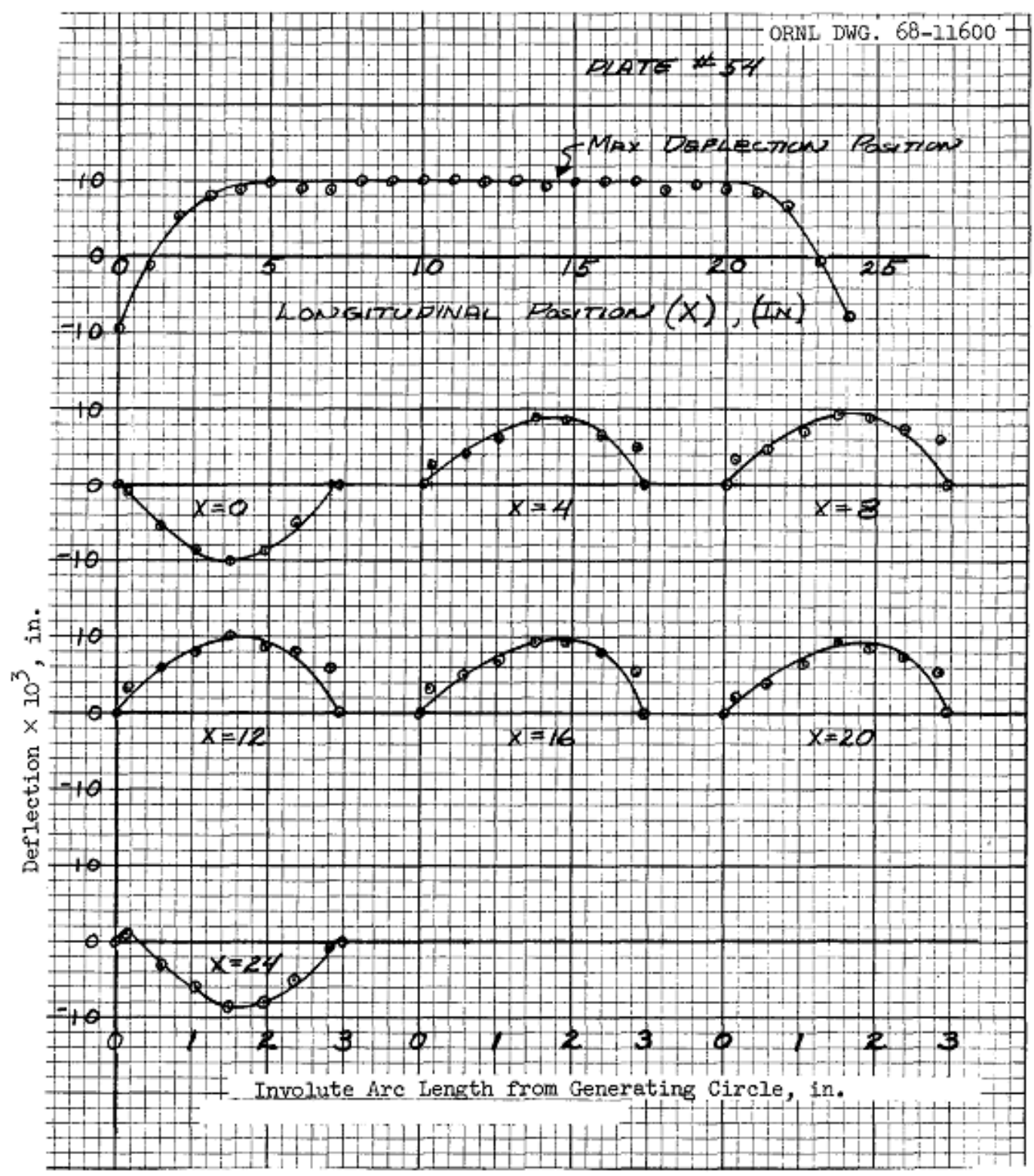

Fig. 7. Experimental results for a fuel plate on a split steel base constrained at its longitudinal edges through 0.25 in. tab attachments (the negative deflections at the top and bottom ends are due to the split base). Transverse (or radial) deflections follow a parabolic profile with peak deflection occurring in midspan of the plate. As shown, longitudinal deflection (along the direction of plate's length) retains its uniform parabolic shape throughout the plate's length with steep gradients at the top and bottom ends [19]. 


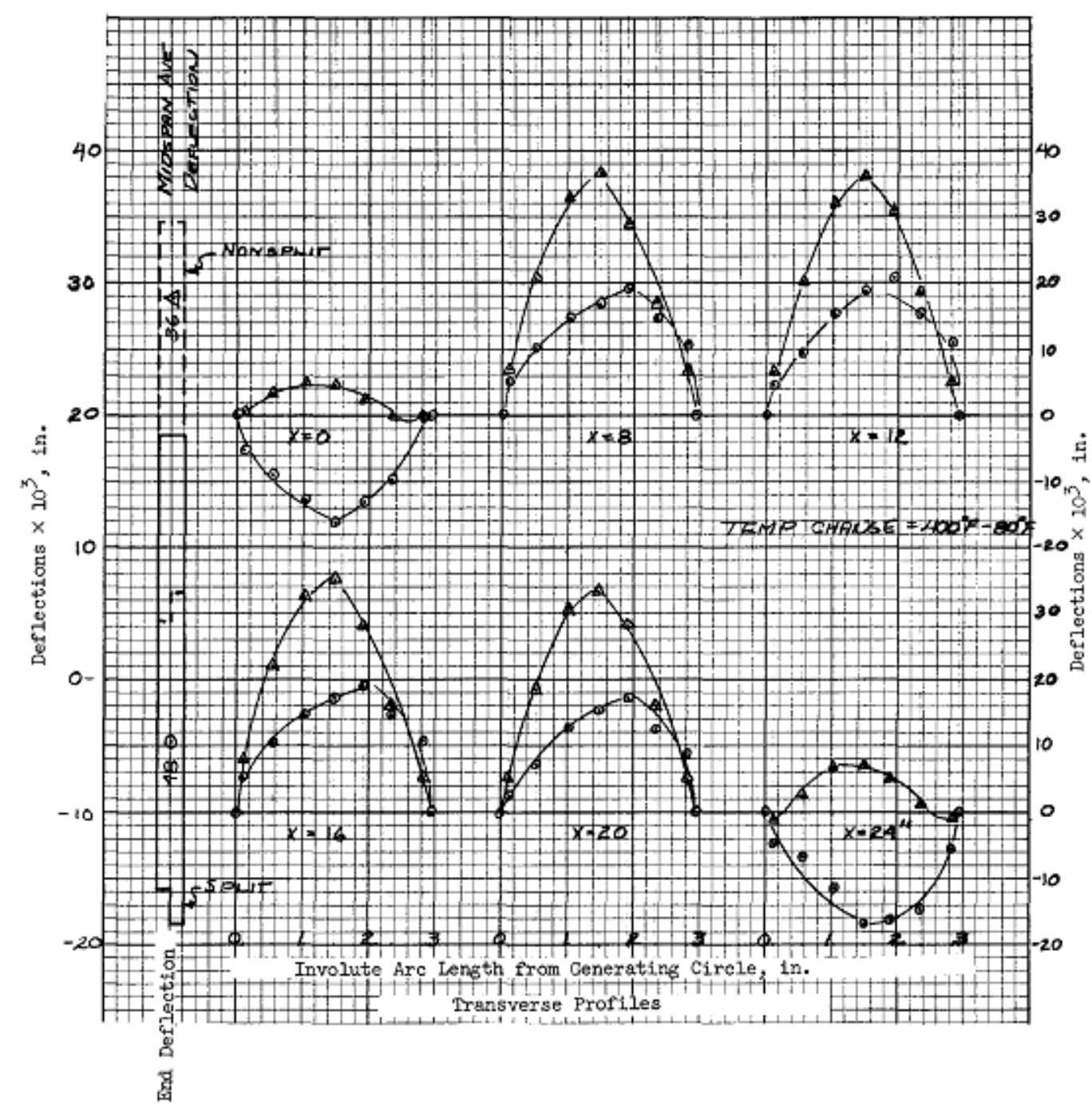

Fig. 8. Experimentally measured transverse deflections (across the plate's radial width) for the outer HFIR fuel plate attached to an Invar base. The instrumented apparatus is heated in an oven from $80^{\circ} \mathrm{F}$ initial temperature to $400^{\circ} \mathrm{F}$. Two transverse profiles at different heights of the plate (in inches) represent deflection results with a solid and a split base of the experiment. In both the experiments, all the tabs $(0.25$ in. thick) of the fuel plate were attached to the Invar base. Transverse deflections follow a parabolic profile with peak deflection occurring at the center of the mid-plane of the plate (at $12 \mathrm{in}$.). Maximum deflection in this experiment was about 37 mil for the solid base (conservative case) and 20 mil (almost half of the solid base experiment) for the split base experiment. Transverse end deflections are relatively minute (5-8 mil) compared with those for the rest of the plate on a solid base; however, on a split base, they tend to be in the opposite direction and are larger in magnitude (16-18 mil). In the figure, triangle markers represent results for the solid base and circles for the split base [19]. 


\section{COMSOL SIMULATIONS OF THE CHEVERTON-KELLEY EXPERIMENTS}

COMSOL Multiphysics is a finite-element-based simulation software whose multiphysics implementation of structural mechanics is based on the principle of virtual work. For stationary simulations, a thermal linear elastic model is used which solves a linear elastic equation for the displacements and the heat conduction model for the temperatures. More details on the governing partial differential equations and their finite element implementation in COMSOL Multiphysics can be found in its theory manuals [18].

In this study, COMSOL is used to perform two sets of simulations for the Cheverton-Kelley experiments. They involved a single test plate constrained along its longitudinal side edges (first set) and a single test plate attached to a solid/split base with a zero displacement boundary condition at its bottom surface (second set). Simulations in the first set provided conservative deflection estimates because of the assumed inherent zero deflection for the base or side plates, whereas those in the second set assessed the qualitative and quantitative accuracy of simulation results as compared with the experiments. Simulations are also performed for the "cold-ended" test plates.

Individual details of the simulations and their results are provided in the following sections:

\subsection{SIMULATION OF SINGLE PLATE WITH CONSTRAINED SIDE EDGES}

A 3D model of HFIR's outer fuel plate is developed in COMSOL Multiphysics, and simulations are performed for the convective heating of the plate - while fully constrained at its side edges - to predict displacements induced by thermal expansion and thermal stresses in the plate. Two scenarios are modeled: (1) an outer test plate made of aluminum and (2) an outer test plate with top and bottom steel ends (a "cold-ended" plate).

\subsubsection{OUTER TEST PLATE MADE OF ALUMINUM}

A 3D model of the HFIR outer test plate is built in COMSOL Multiphysics and shown in Fig. 9. The model plate is made of a single material (aluminum). As a model simplification, the HFIR fuel plate's internals - contoured fuel meat and poison - are not explicitly modeled. However, the model does take into account the straight extensions of the test plates that fit into the side plate grooves.

In the model, the plate is fully constrained at its longitudinal side edges where they meet the side plates (i.e., zero displacement boundary condition at the edges). A convective heat transfer coefficient equal to 5 $\mathrm{W} / \mathrm{m}^{2}-\mathrm{K}$ is assumed at all of the plate's surfaces to represent its slow heating in an oven. The bulk oven temperature is assumed to be $400^{\circ} \mathrm{F}$; the initial temperature of the plate is assumed to be $80^{\circ} \mathrm{F}$.

Results for the steady-state deformation of the aluminum test plate are shown in Fig. 10. The test plate tends to deform toward the convex side of the involute. Deformation follows a parabolic (or sinusoidal) profile over most of the plate except at its top and bottom ends, peaking in the central region of the involute arc. Deformations at the bottom and top ends are relatively minor compared with that for most of the plate. Figure 11 shows unscaled deformations at several cross sections of the test plate. 


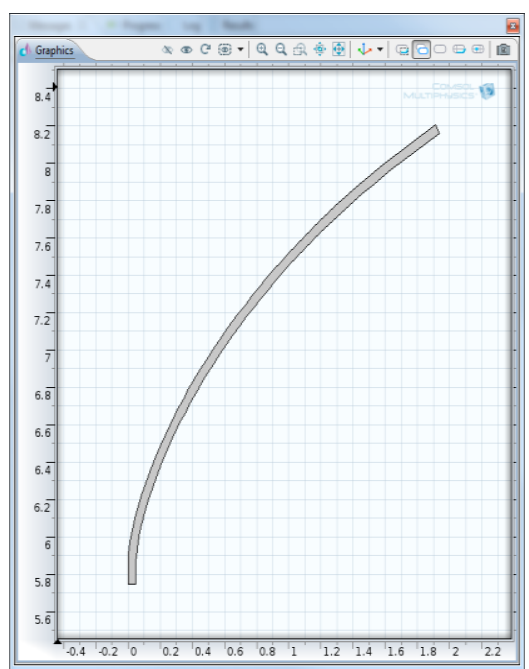

(a)

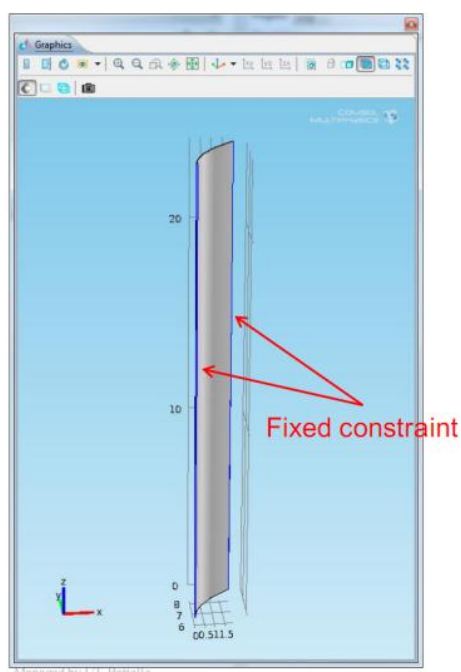

(b)

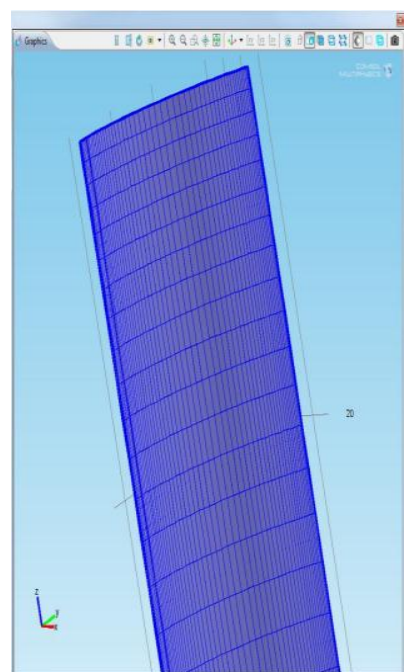

(c)

Fig. 9. (a) Cross-sectional face of the involute plate sketched on a 2D work-plane in COMSOL Multiphysics. (b) 2D involute surface is extruded in the $z$-direction to generate the outer test plate in 3D. Fixed constraints (all the displacements are restricted to be zero) are applied at both longitudinal edges of the plate. (c) A nonuniform mapped mesh is generated for the plate. Distribution of elements can be individually controlled in the direction of plate thickness, width, and length.

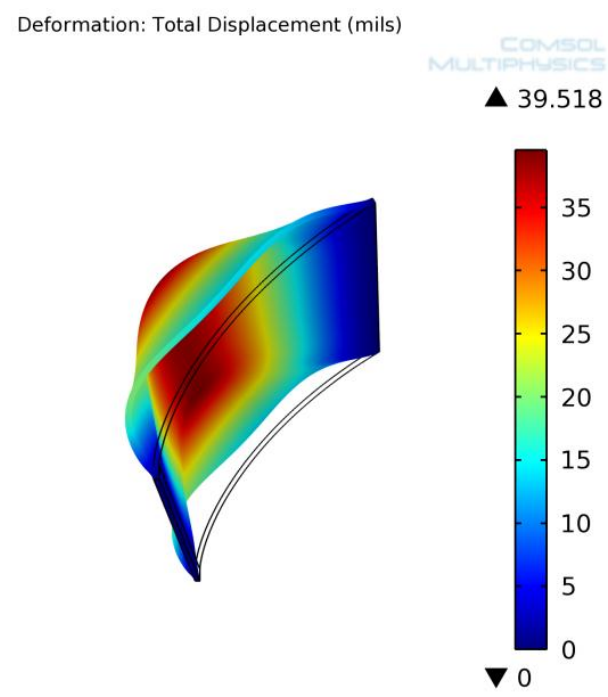

(a)

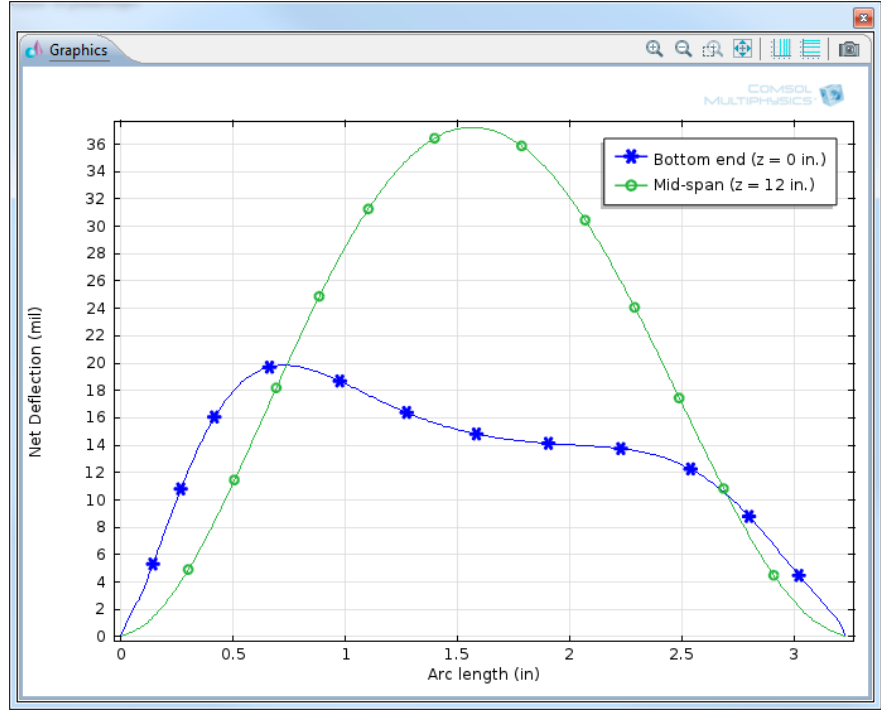

(b)

Fig. 10. (a) Deformation in the HFIR outer test plate due to thermal expansion caused by its convective heating from $80^{\circ} \mathrm{F}$ to $400^{\circ} \mathrm{F}$. The plate is fully constrained on both of its longitudinal sides. Deformation is in units of mil and is scaled up 20 times for ease of viewing. (b) Fuel plate deflections at the bottom end $(z=0$ in.) and mid-span $(z=12$ in.) of the plate. The highest deflection occurs at the mid-span of the plate; deflections are considerably smaller at the bottom and top ends (not shown, same as the bottom end due to symmetry). Unlike the longitudinal midplane, the plate at these ends may not deflect symmetrically across the involute width. 


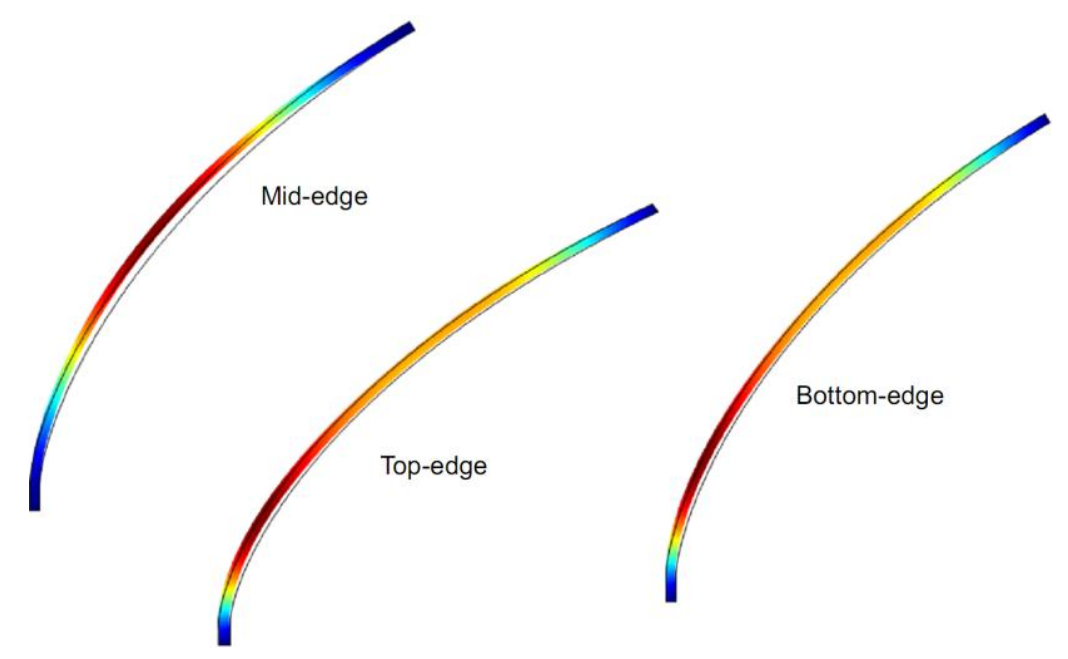

Fig. 11. Temperature-induced deflections - with no viewgraph scaling — at different cross sections of HFIR's outer test plate in the COMSOL Multiphysics simulation results. Deflections are highest at the midspan of the plate.

In Fig. 12, longitudinal variation of thermal deflection is shown for the location of stylus no. 4 (approximate middle of the plate's radial width) in the Cheverton-Kelley experiment. Variation is found to be uniform along most of the plate's length except its top and bottom ends. A steep gradient of deflection is seen in the top and bottom two inches of the plate.

At the location of transformer \# 4

in "Cheverton-Kelley" experiments
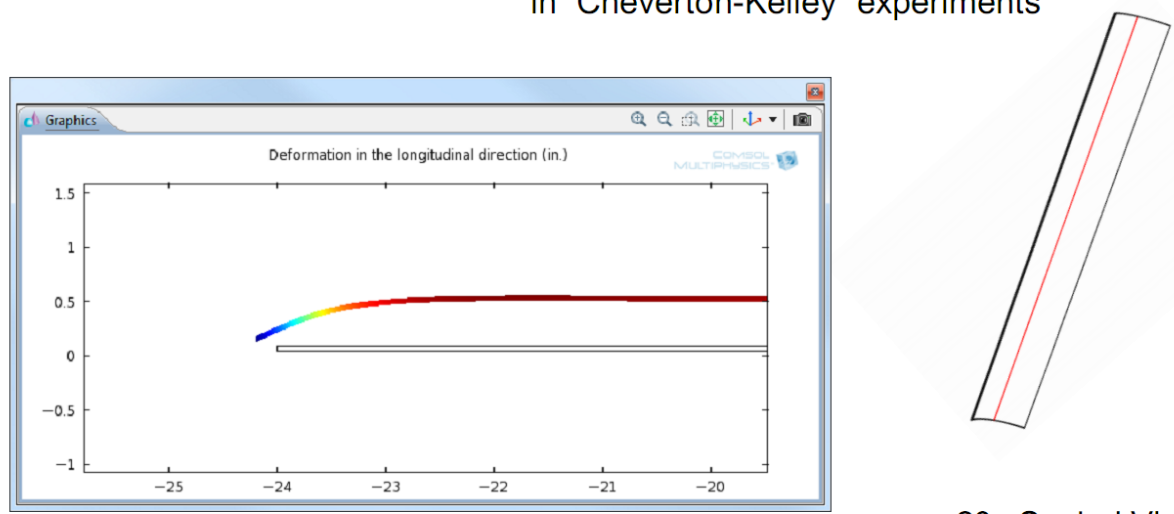

20x Scaled View

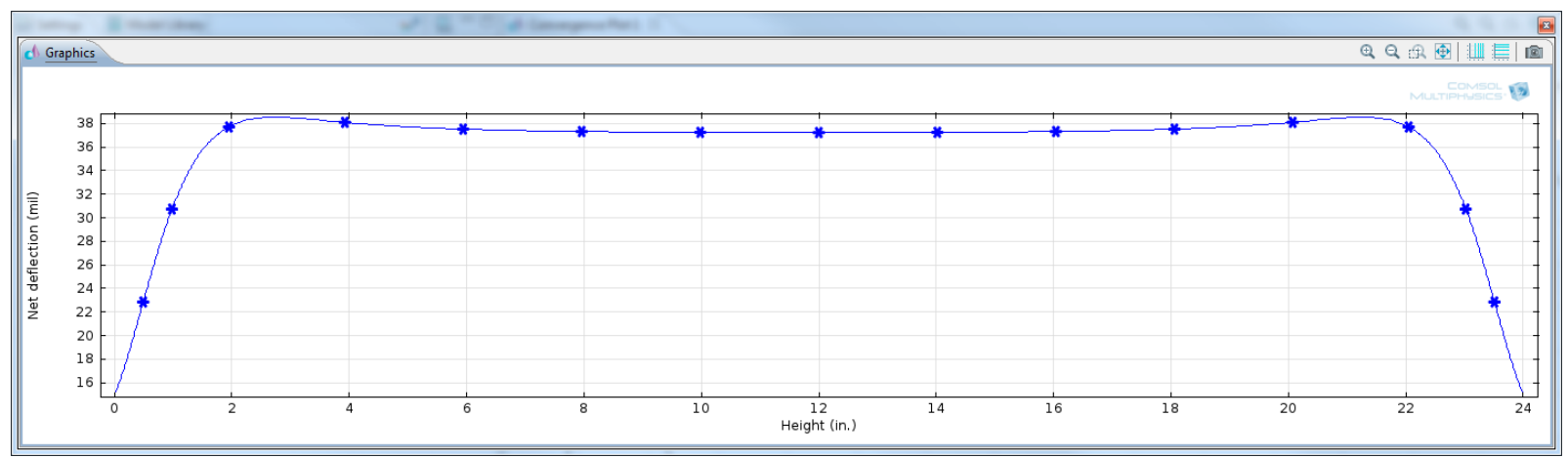

Fig. 12. A plate's deflection in mil along its length at its longitudinal center plane (1.54 in. arc length from the left edge of the plate). The deflection profile is almost flat (uniform) in most of the plate except its top and bottom ends. 


\subsubsection{COLD-ENDED OUTER TEST PLATE}

To simulate the cold ends of the Cheverton-Kelley experiments, the 3D model of the plate discussed earlier is modified to include a 2 in. long steel section at the top and bottom ends of the plate. A convective heat transfer coefficient of $5 \mathrm{~W} / \mathrm{m}^{2}-\mathrm{K}$ with $400^{\circ} \mathrm{F}$ bulk temperature is applied to all surfaces of the plate, and the plate is modeled to be fully constrained along its longitudinal edges. A 3D model along with the meshing used is shown in Fig. 13.

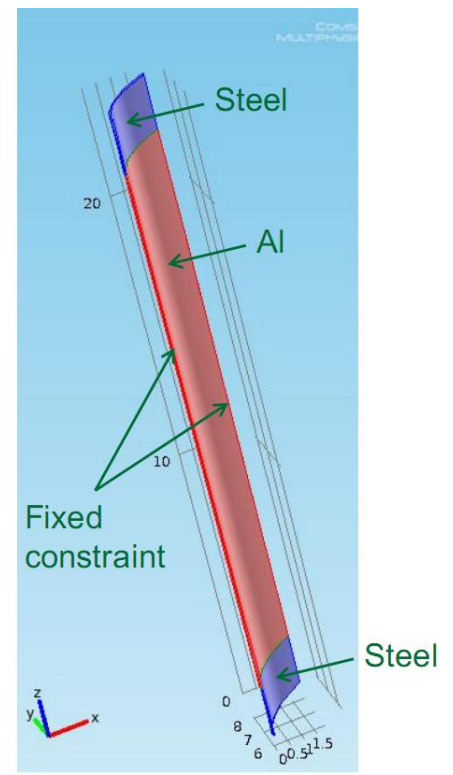

(a)

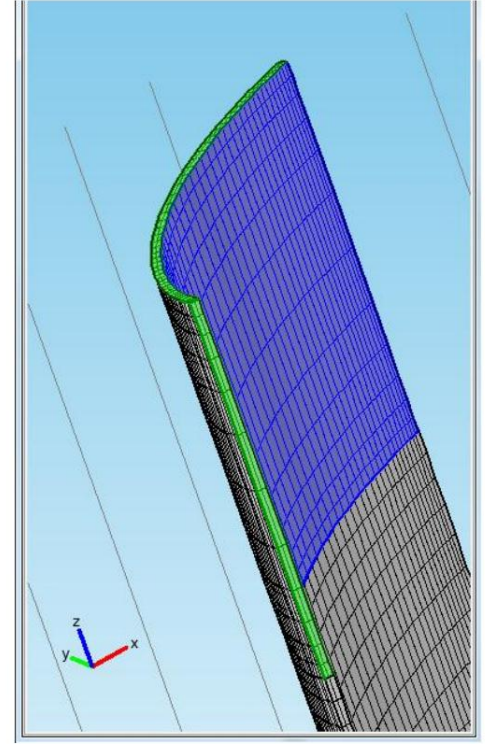

(b)

Fig. 13. (a) COMSOL Multiphysics model of HFIR's outer test plate with cold (steel) ends. An aluminum plate with 2 in. long steel ends attached to its top and bottom was simulated in COMSOL Multiphysics for convective heatup and resulting temperature-induced deflections. (b) A usercontrollable mapped mesh is shown for the cold-ended plate.

Deflections are shown in Fig. 14, which is a 20x scaled viewgraph. The magnitude and shape of the deflections for most of the plate do not vary much from the results presented in Sect. 5.1.1; however, at the top and bottom ends, the gradient of deformation in longitudinal direction is relatively steeper due to the constraints imposed by the lower thermal expansion of the steel ends. The magnitude of maximum deflection remains almost the same as that for the regular aluminum plate. The resulting deflections are plotted in Figs. 15 and 16 for different cross-sectional planes. Steep variation of deformation at the plate's ends is better observed in Fig. 16, where longitudinal variation is plotted. In most of the plate away from its ends, the shape of deflection across the plate's involute remains constant. 

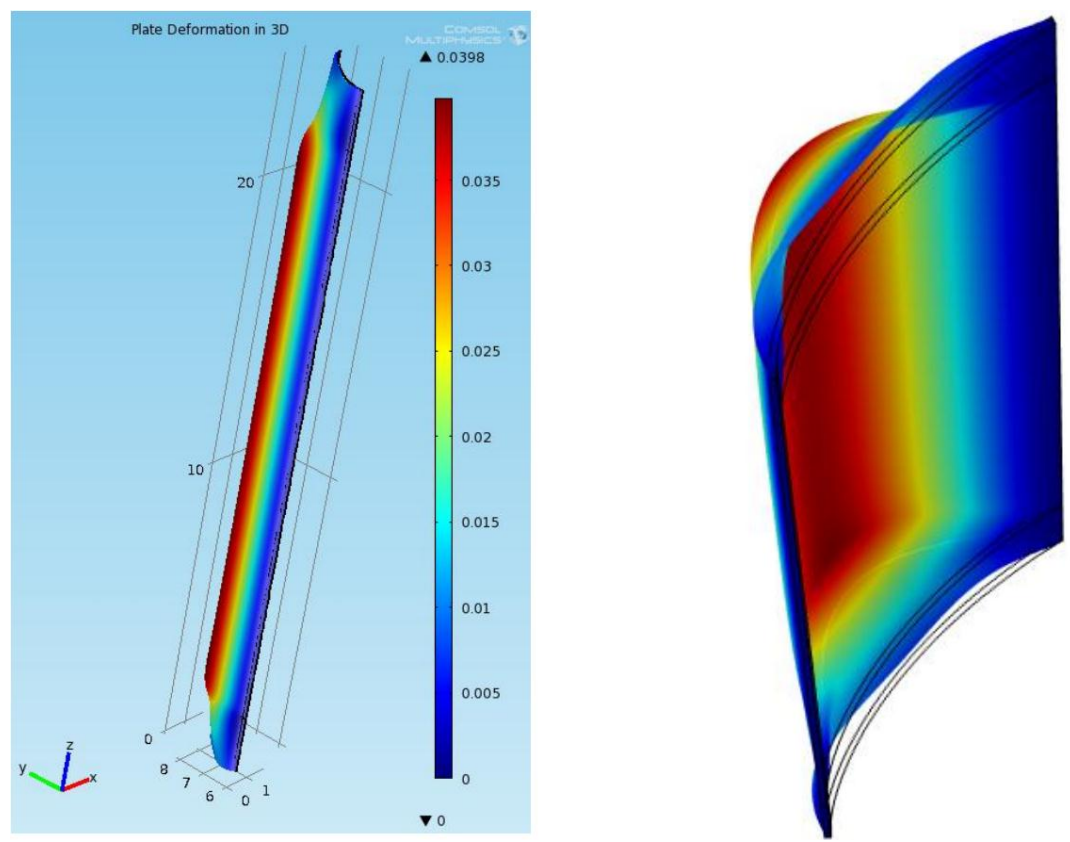

Fig. 14. Deformation in the cold-ended outer test plate due to thermal expansion caused by convective heating from $80^{\circ} \mathrm{F}$ to $400^{\circ} \mathrm{F}$. The plate is fully constrained on both of its longitudinal sides. Deformations at the top and bottom ends are considerably smaller than those of the test plate with no cold ends (see Fig. 10 for comparison). (Deformations in the viewgraphs are in units of inches and are scaled up $20 \times$ for the ease of viewing.)

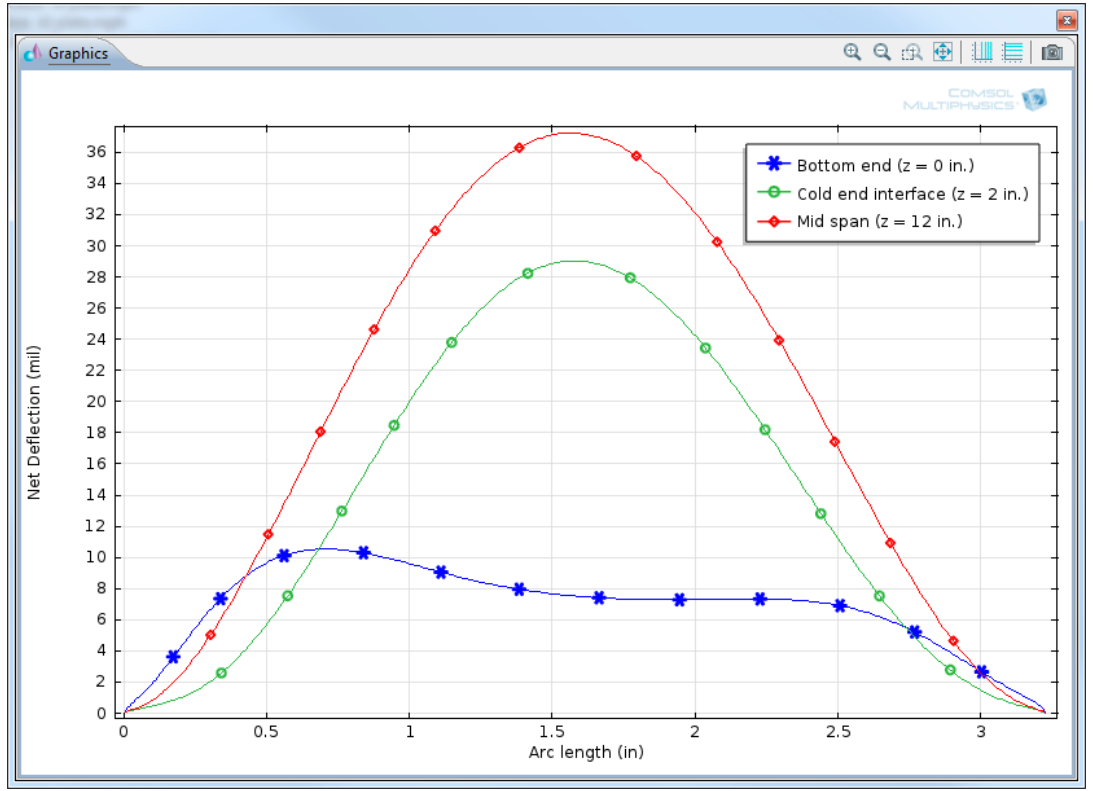

Fig. 15. Deflections at the bottom end $(z=0$ in.), cold end interface $(z=2$ in.) and at mid-span $(z=12$ in.) of the cold-ended outer test plate. Maximum deformation at the mid-plane is almost same as it is for its counterpart in Fig. 10(b); however, deflections at the top (not shown) and bottom ends are almost half that of the regular test plate with no cold ends. 
At the location of transformer \# 4

in "Cheverton-Kelley" experiments
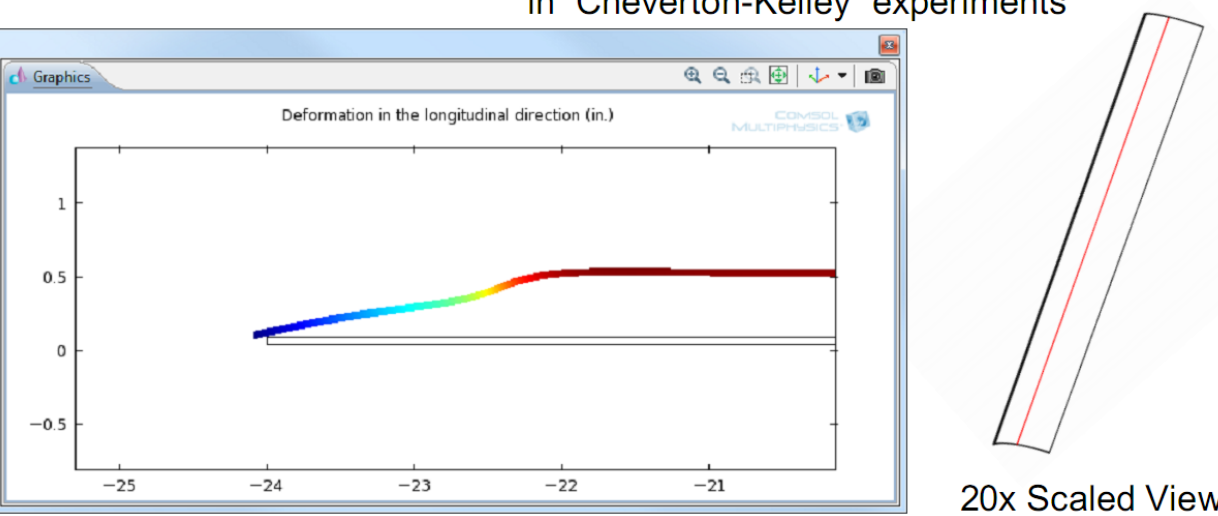

20x Scaled View

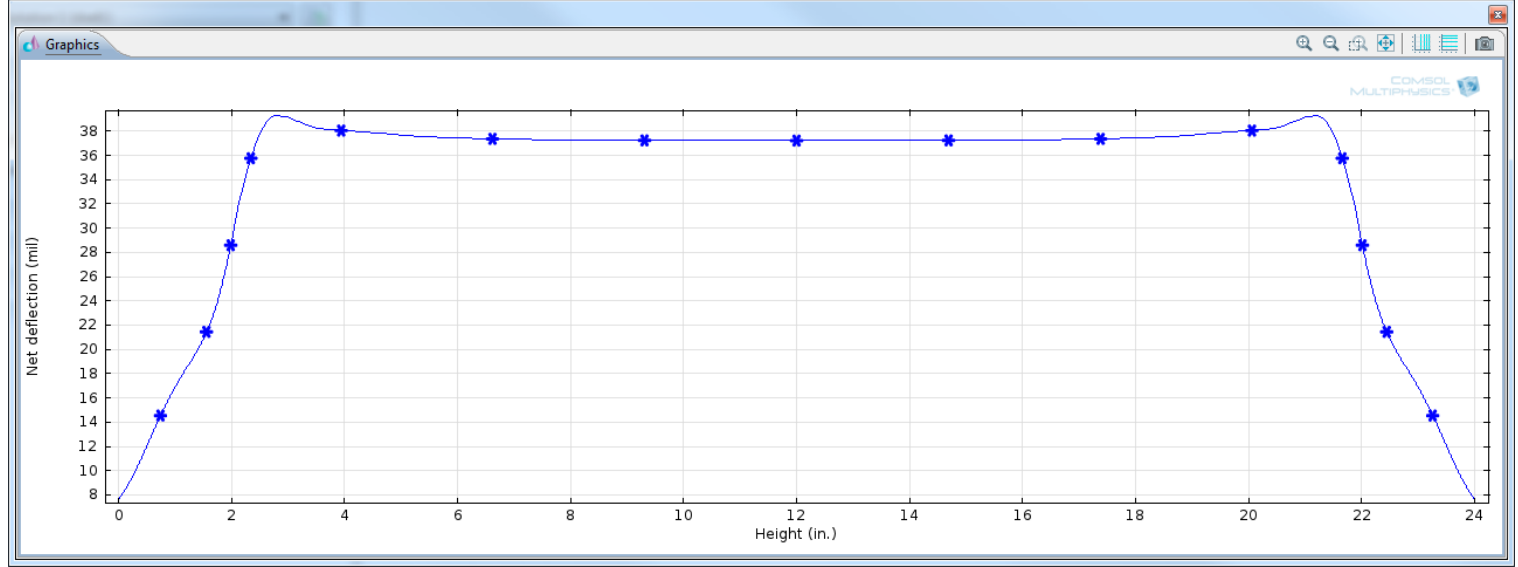

Fig. 16. Cold-ended plate's deflection along its length at its longitudinal center plane (1.54 in. arc length from the left edge of the plate) (in mil). The deflection profile is almost flat (uniform) in most of the plate except its top and bottom ends. Also, slope of the deformation at the ends of the plate is relatively steep, compared with that shown in Fig. 12. The steeper slope is due to restraints caused by the steel ends.

\subsection{SIMULATION OF TEST PLATE ATTACHED TO A BASE}

In order to capture the experimental details more accurately in simulations, the base to which the plate was attached in experiments is modeled explicitly in COMSOL Multiphysics. Drawings for the base design were obtained from ORNL Research Reactor Division's Drawing Database (Drawing nos. E49928, E49929, E49936, E50152, E50158, E50165, E50166 and E50167) and approximate computeraided design (CAD) geometry was developed. Key geometric features of the base that affect differential thermal expansion of the plate are modeled accurately (e.g., involute edges of the base in contact with the plate's longitudinal side edges and the base geometry-solid or split). Figure 17 shows the drawing for the cross-section of the base used in experiments. Figure 18 shows the modeled CAD geometry and the meshing used in the simulations. Notice a restraining bar attached to the base at its top and bottom ends. 


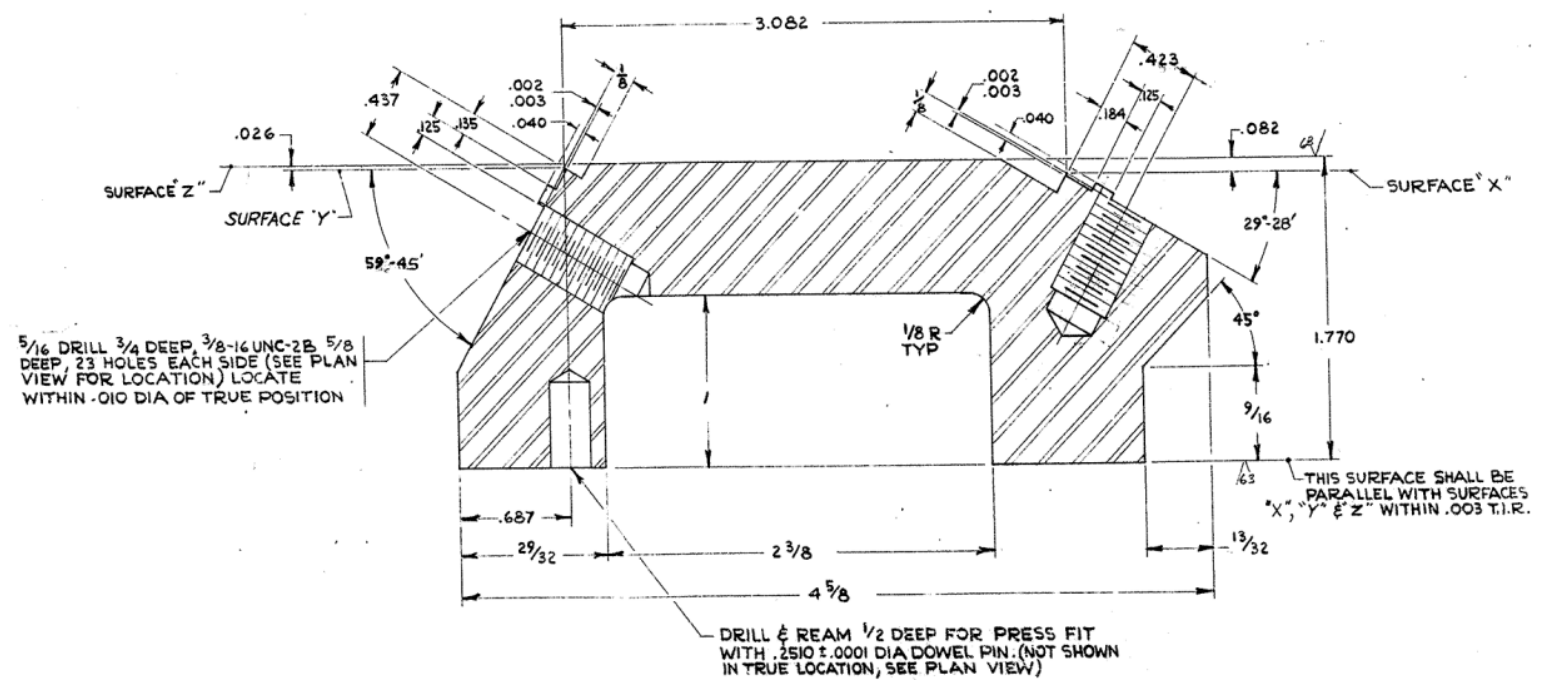

Fig. 17. Drawing for the base geometry (dimensions in inches) used in the Cheverton-Kelley tests (source: drawing no. E50166).

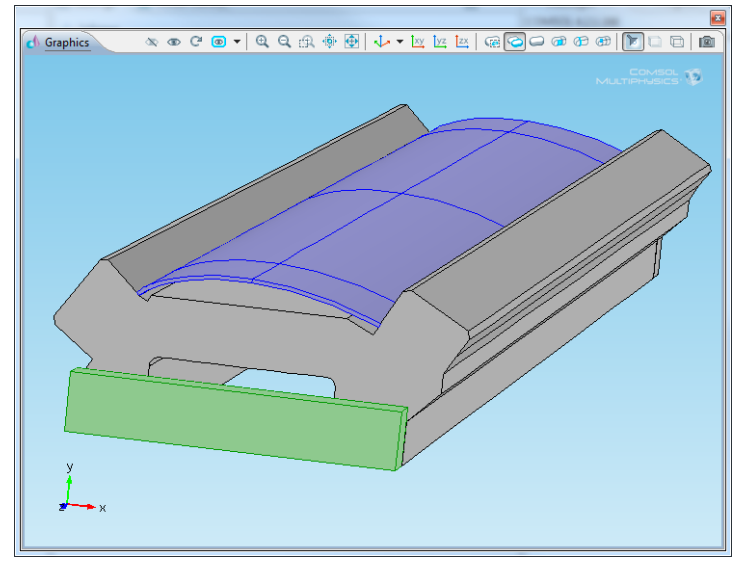

(a)

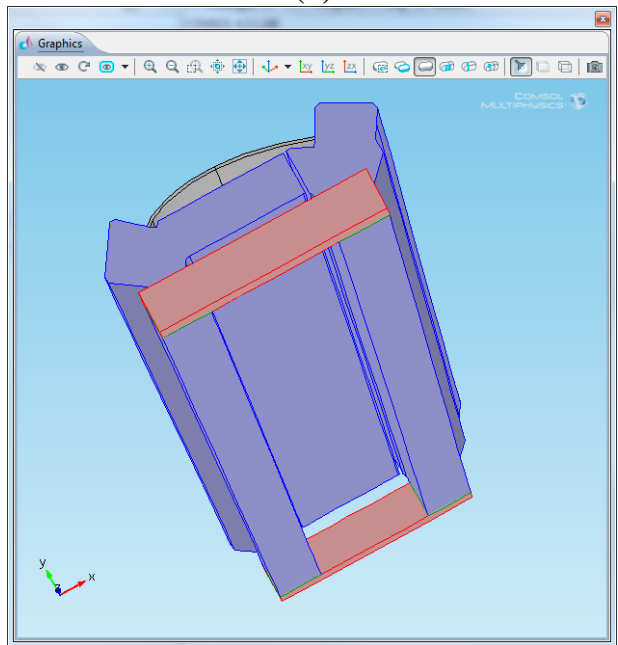

(c)

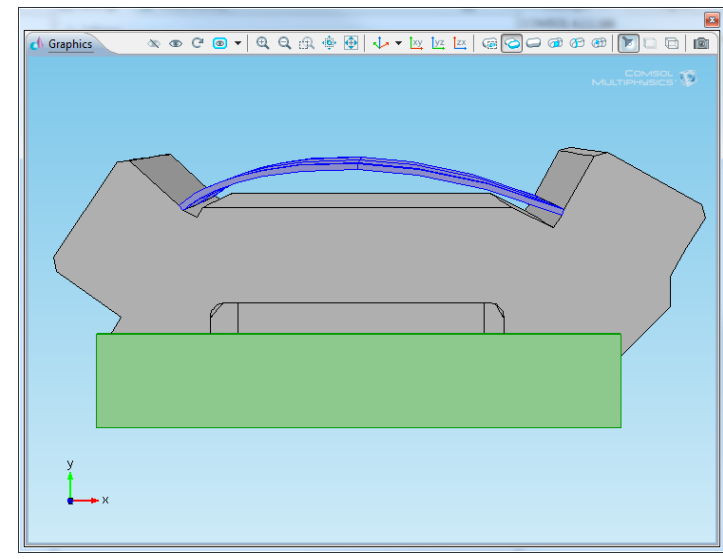

(b)

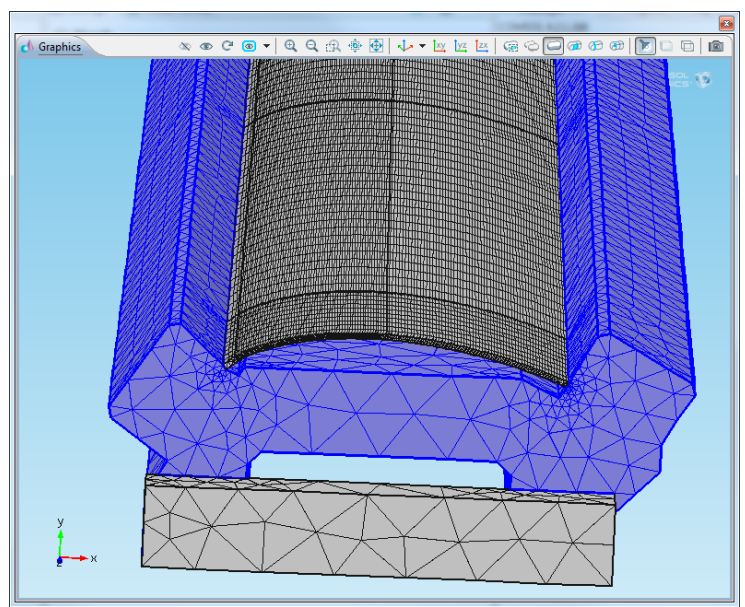

(d)

Fig. 18. CAD geometry and meshing developed for the simulation of differential thermal expansion in Cheverton-Kelley experiments. 
Two types of simulations are performed: (1) an aluminum plate attached to solid/split steel and Invar bases and (2) cold-ended aluminum plate attached to a solid/split Invar base. Choice of these simulations is dictated by the available experimental data. In all of the simulations, a zero-displacement boundary condition in the $y$-direction is applied at the bottom of the base, restricting its displacement perpendicular to the base surface. All the other surfaces are free to deform in any direction depending on their thermal stresses. Similar to models discussed earlier, a convective heat transfer boundary condition is applied to all the surfaces of the plate and the base. Details of the individual simulations are provided in the following sections.

\subsubsection{ALUMINUM PLATE WITH SOLID/SPLIT STEEL AND INVAR BASES}

Deflection results for the aluminum test plate attached to a solid and a split steel base are shown in Figs. 19 and 20, respectively. Contours in 3D as well as deflections at selected cross-sectional edges (bottom end, mid-span and longitudinal center plane) are provided. Corresponding simulation results for an Invar base are shown in Figs. 21 and 22.

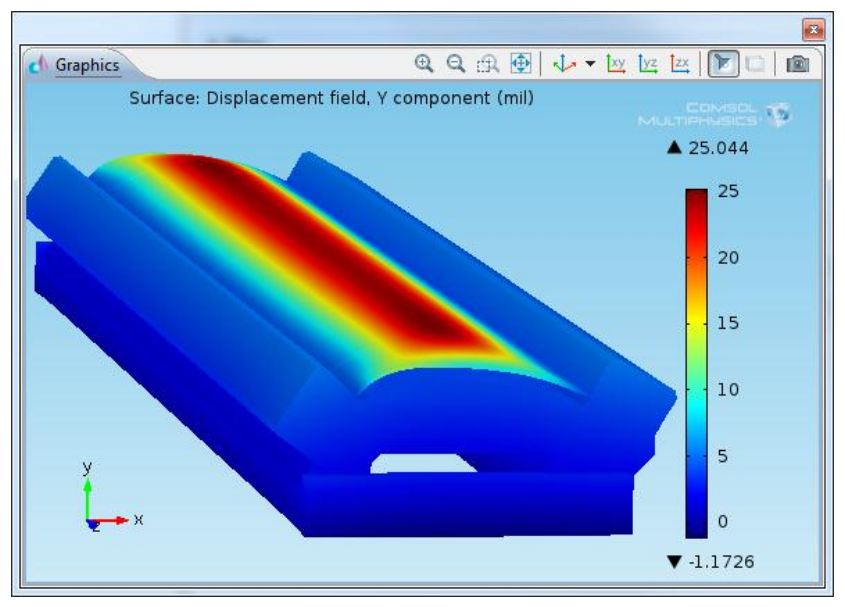

(a)

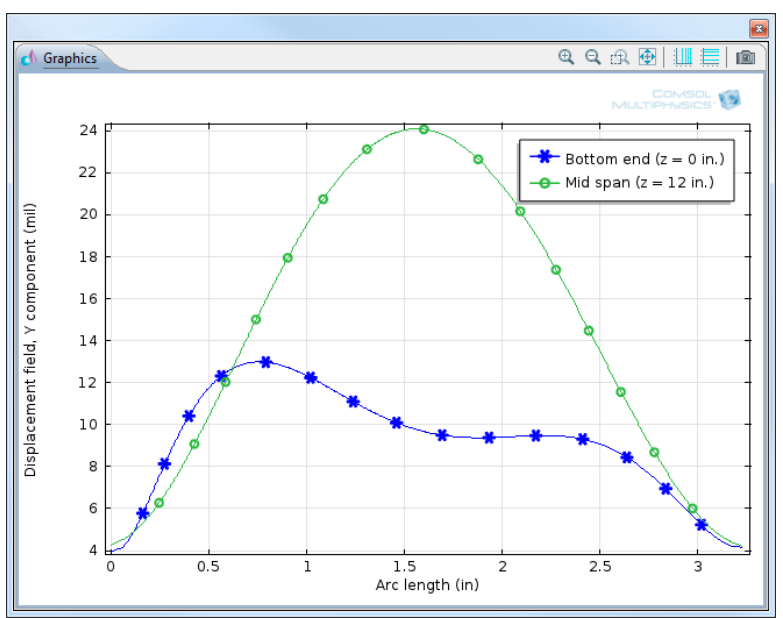

(b)

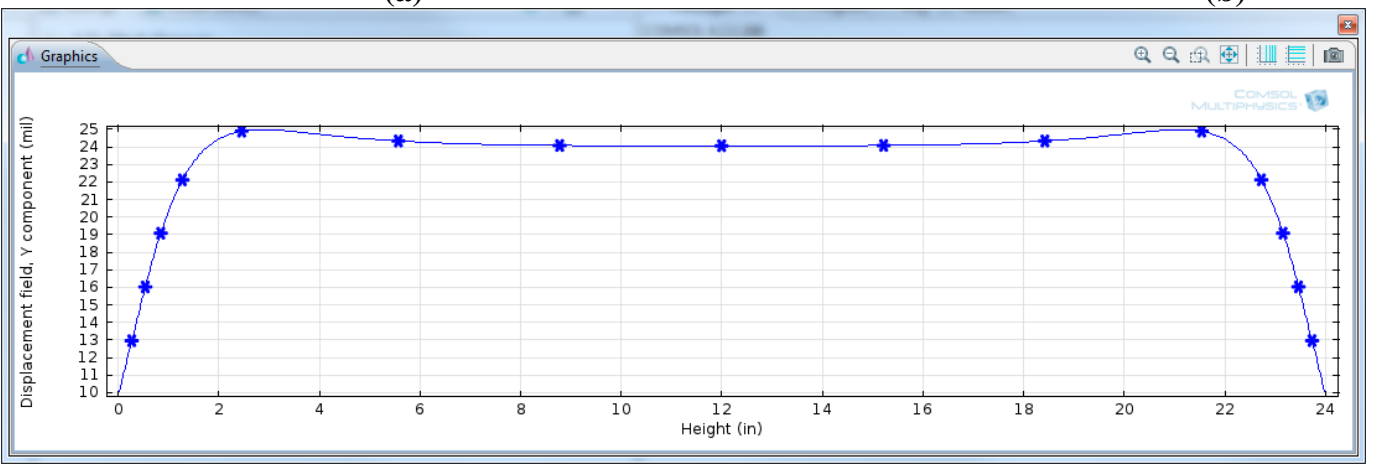

(c)

Fig. 19. Aluminum plate attached to a solid steel base. (a) $y$-direction component of the deformation field (approximately representing the plate's deflection perpendicular to its convex surface); (b) the plate's $y$ deflection at its bottom end ( $z=0 \mathrm{in}$.) and at its mid-span $(z=12 \mathrm{in}$.); (c) the plate's $y$-deflection along its length at its longitudinal center plane (1.54 in. arc length from the left edge of the plate). 


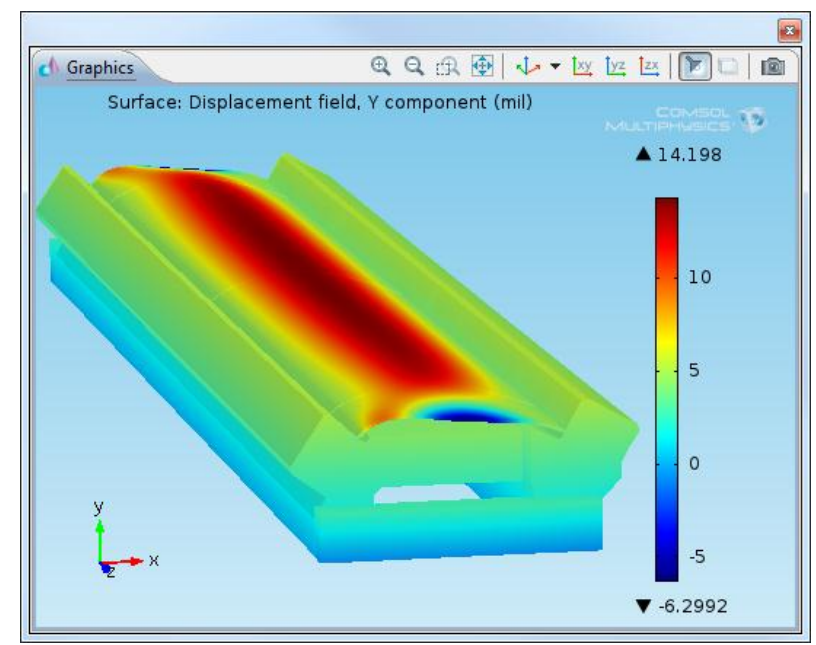

(a)

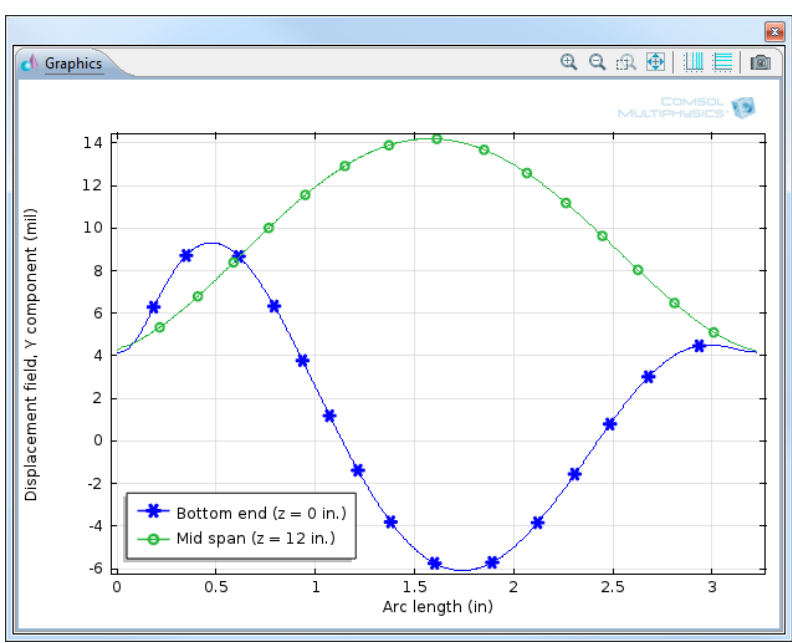

(b)

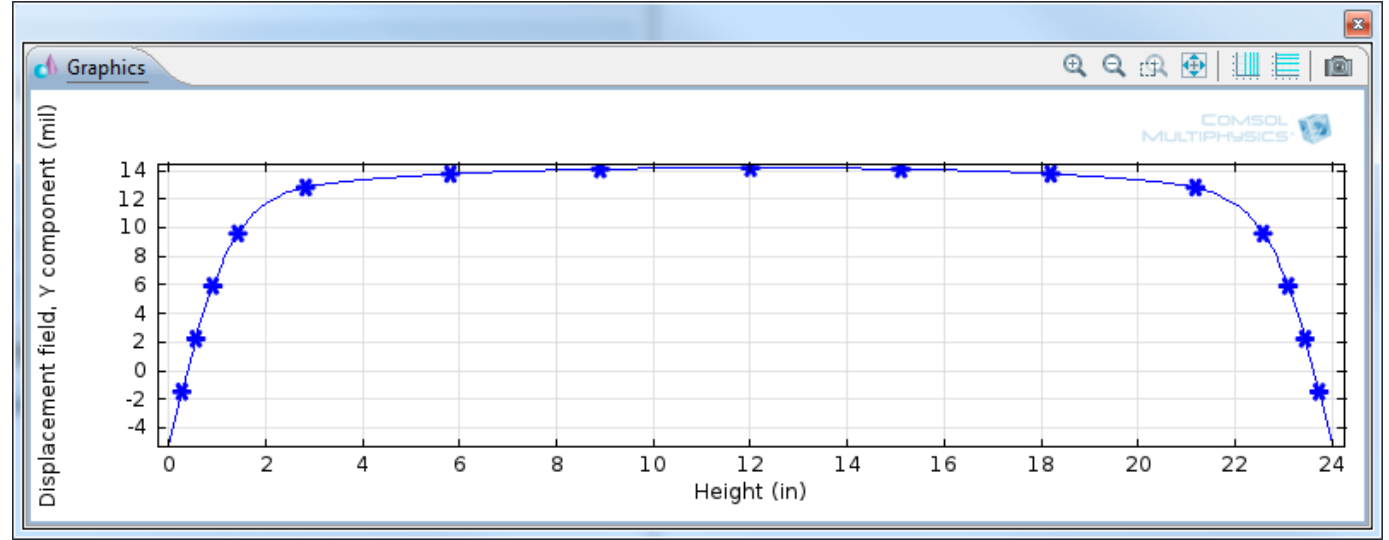

(c)

Fig. 20. Aluminum plate attached to a split steel base. (a) $y$-direction component of the deformation field; (b) the plate's $y$-deflection at its bottom end ( $z=0$ in.) and at its mid-span $(z=12$ in.); (c) the plate's $y$-deflection along its length at its longitudinal center plane. 


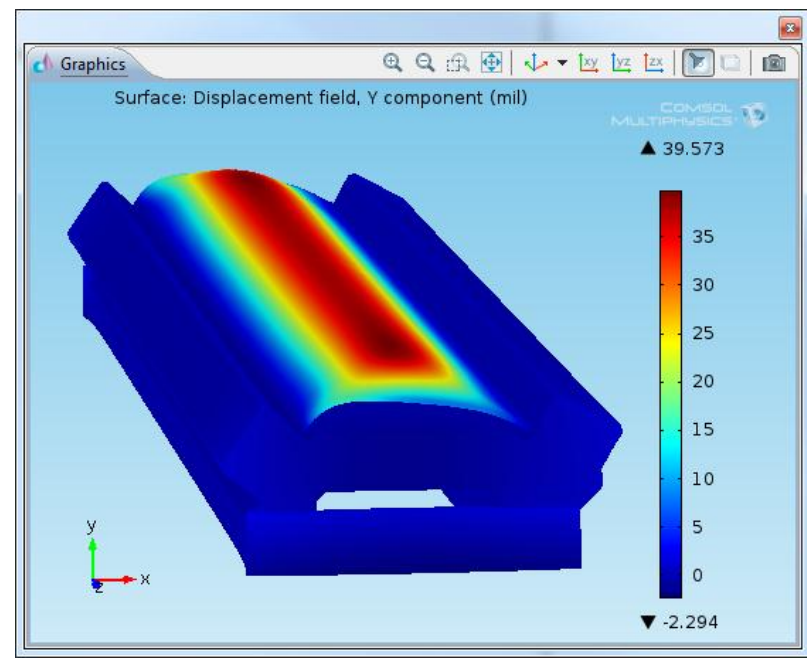

(a)

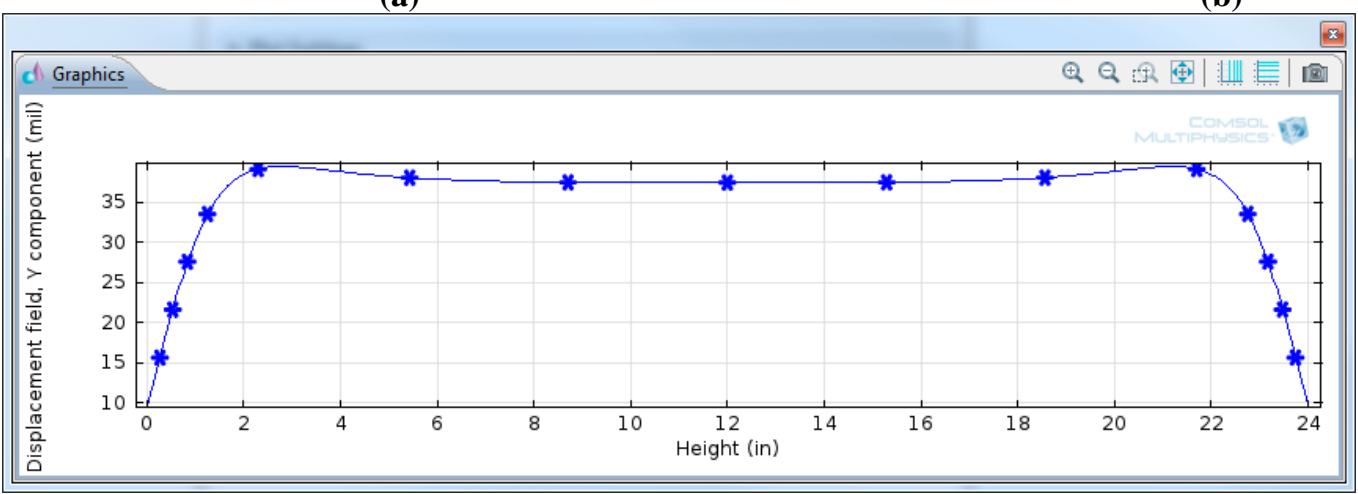

(c)

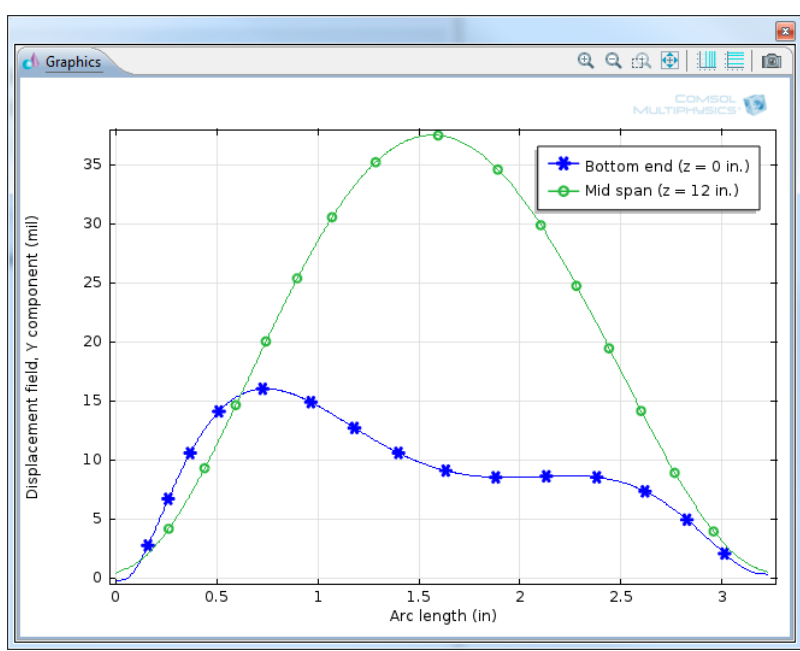

(b)

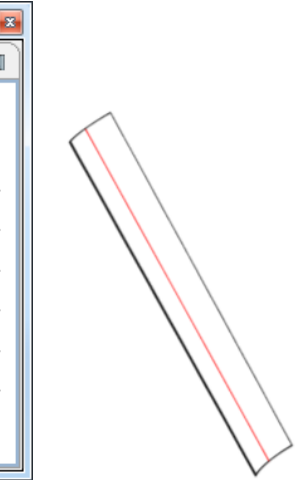

Fig. 21. Aluminum plate attached to a solid Invar base. (a) $y$-direction component of the deformation field; (b) the plate's $y$-deflection at its bottom end ( $z=0$ in.) and at its mid-span ( $z=12 \mathrm{in.}$ ); (c) the plate's $y$-deflection along its length at its longitudinal center plane. 


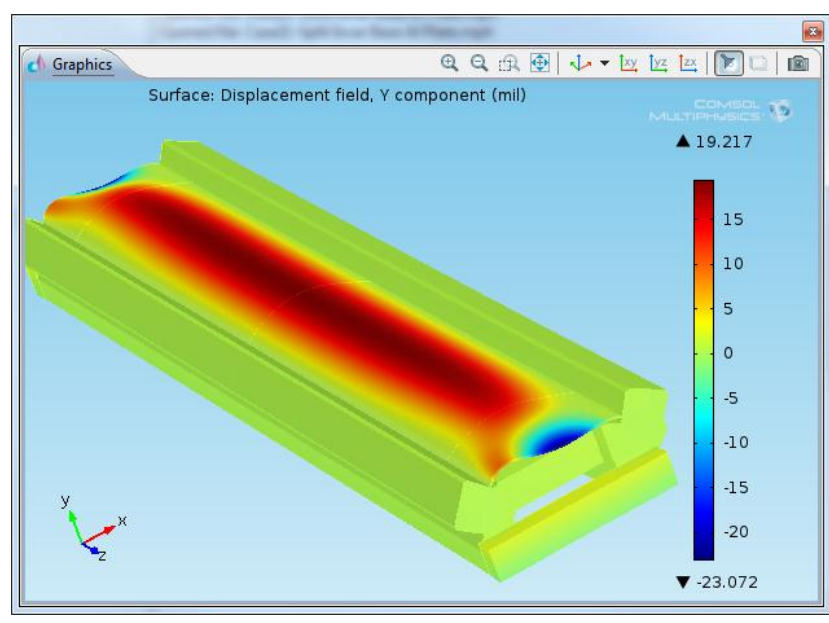

(a)

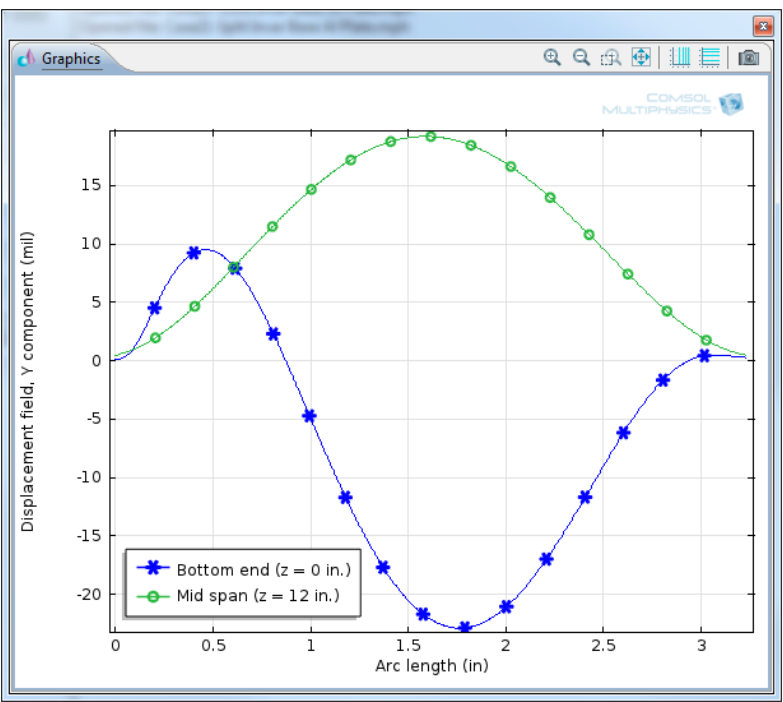

(b)

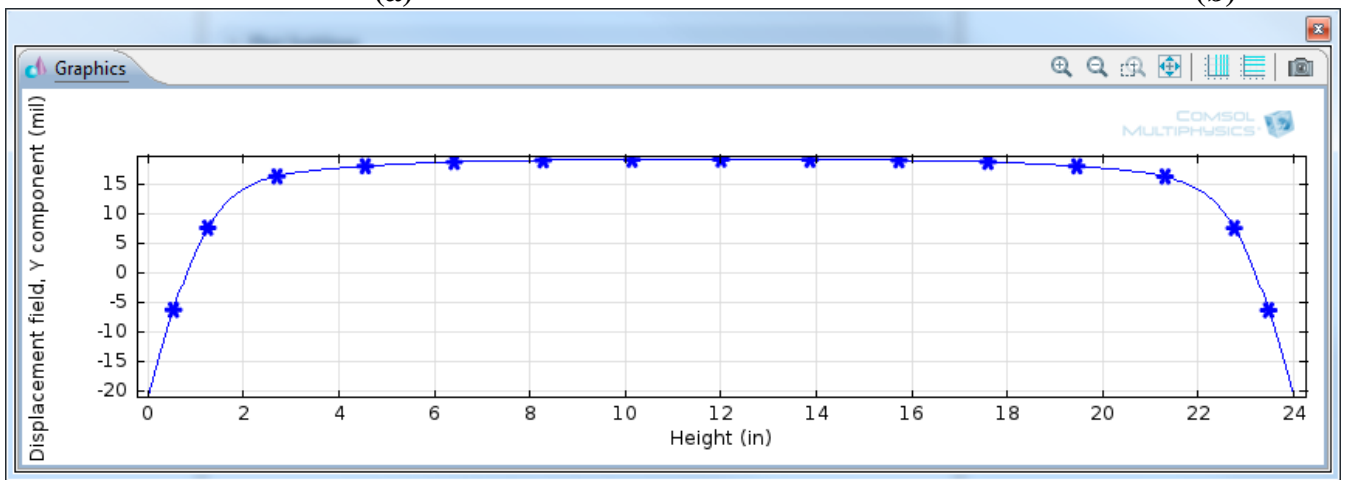

(c)

Fig. 22. Aluminum plate attached to a split Invar base. (a) $y$-direction component of the deformation field; (b) the plate's $y$-deflection at its bottom end ( $z=0$ in.) and at its mid-span $(z=12$ in.); (c) the plate's $y$-deflection along its length at its longitudinal center plane.

\subsubsection{COLD-ENDED ALUMINUM PLATE WITH SOLID/SPLIT INVAR BASE}

Deflection results for the cold-ended aluminum test plate attached to a solid and a split Invar base are shown in Figs. 23 and 24, respectively. Contours in 3D as well as deflections at selected cross-sectional edges (bottom end, mid-span, cold-end interface, and longitudinal center plane) are provided. 


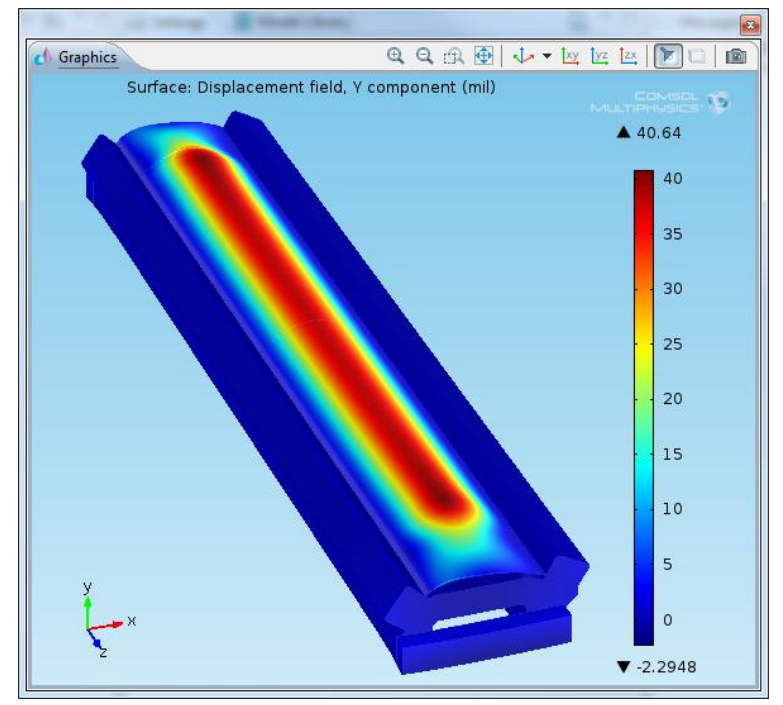

(a)

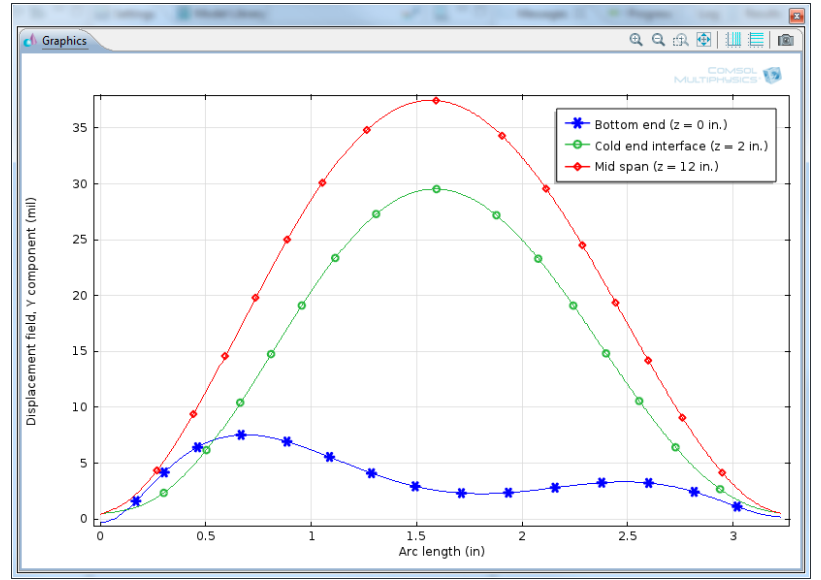

(b)

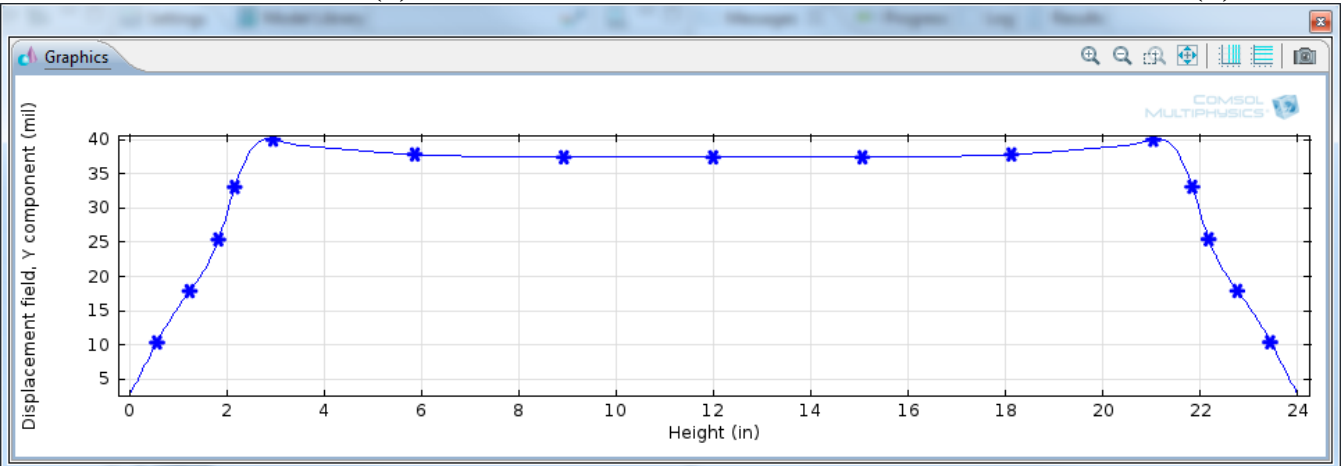

(c)

Fig. 23. Cold-ended aluminum plate attached to a solid Invar base. (a) $y$-direction component of the deformation field; (b) the plate's $y$-deflection at its bottom end $(z=0$ in.), at its interface with steel end $(z=2$ in.) and at its mid-span ( $z=12$ in.); (c) the plate's $y$-deflection along its length at its longitudinal center plane. 


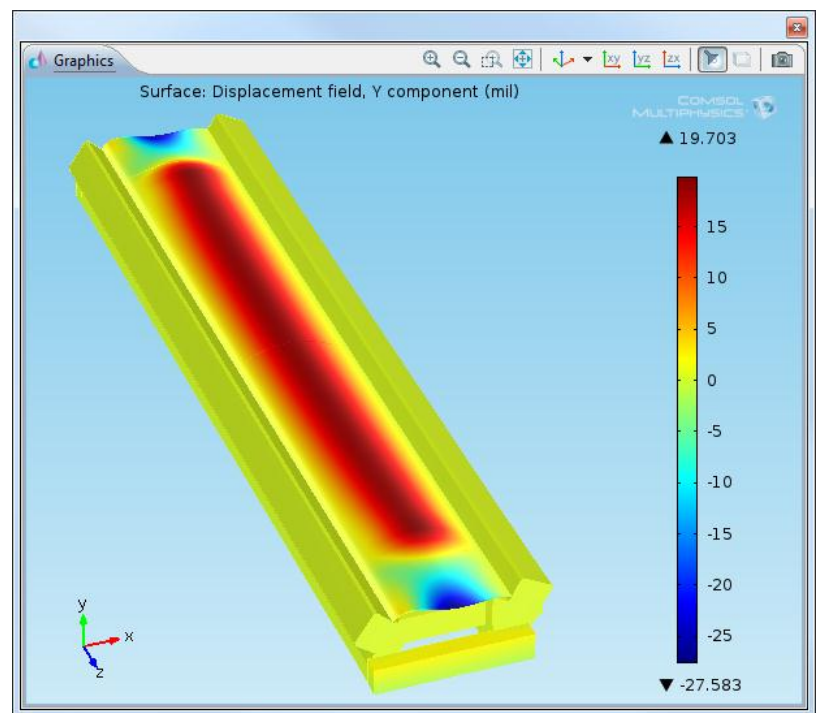

(a)

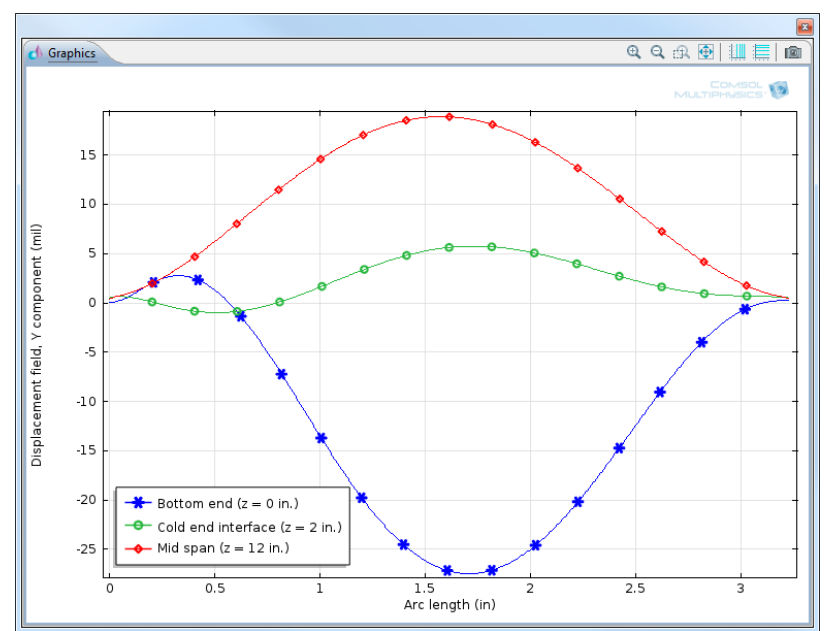

(b)

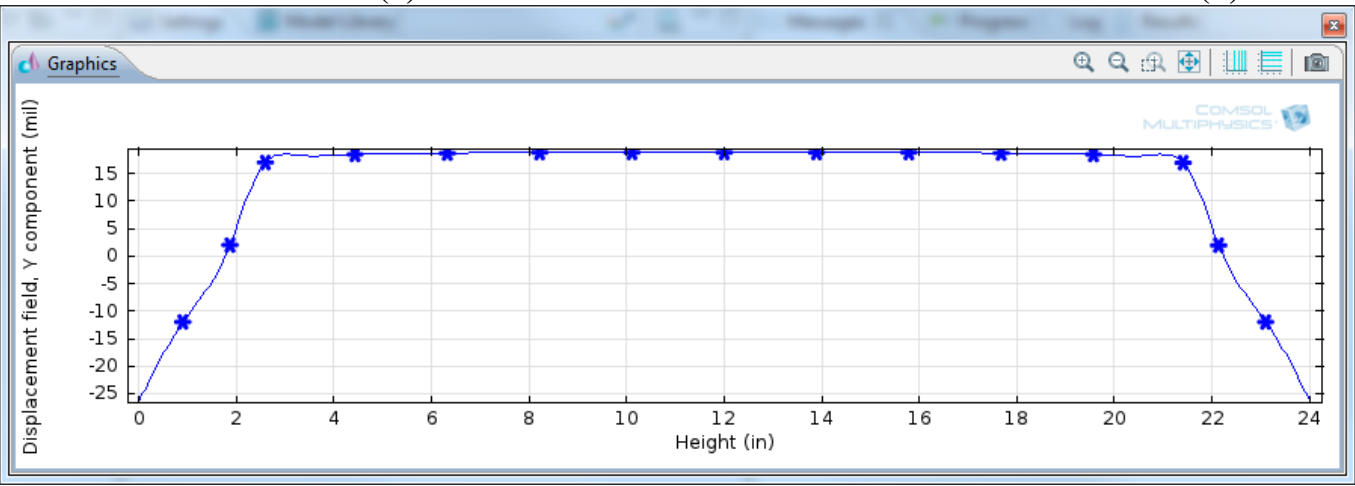

(c)

Fig. 24. Cold-ended aluminum plate attached to a split Invar base. (a) $y$-direction component of the deformation field; (b) the plate's $y$-deflection at its bottom end ( $z=0$ in.), at its interface with steel end $(z=2$ in.) and at its mid-span ( $z=12$ in.); (c) the plate's $y$-deflection along its length at its longitudinal center plane. 


\section{COMPARISON OF SIMULATION RESULTS WITH EXPERIMENTAL DATA FOR VALIDATION}

Simulation results presented earlier are in good qualitative and quantitative agreement with findings from the Cheverton-Kelley experiments. Considering several differences between the COMSOL models and the actual experiments (e.g., simplified CAD geometry in simulations, fuel plate represented by a homogenous material in simulations, tab attachments at the longitudinal sides of the plate in experiments, and best estimate material properties used in the models), simulation results show a very good quantitative agreement (within engineering limits) and a very accurate qualitative behavior (variation of deflection profile with changes in material or physical constraints) with the experimentally acquired data.

Detailed measurement data are only available for two of the experiments (see Figs. 7 and 8 ) in which the outer fuel plate is constrained to the base with tab attachments. The data were compared with the simulation results for the aluminum plate firmly attached (bonded) with the solid and split base. Figure 25 shows a comparison of mid-span deflections of an aluminum plate attached with Invar base. The comparison shown in Fig. 26 is for an aluminum plate attached with a split steel base. Deflection data for the mid-span ( $z=12$ in.) and across the plate's longitudinal length show a very good agreement with the experiments. Qualitatively, simulation results are able to capture the plate's deflection behavior accurately.

Several peak deflection measurements in experiments are compared with their best-estimate simulation model results in Table 3. Amid a large scatter of these experimental measurements with slight changes in plate's attachment to the base [19], these comparisons demonstrate a good engineering agreement between the experiments and their best-estimate simulations.

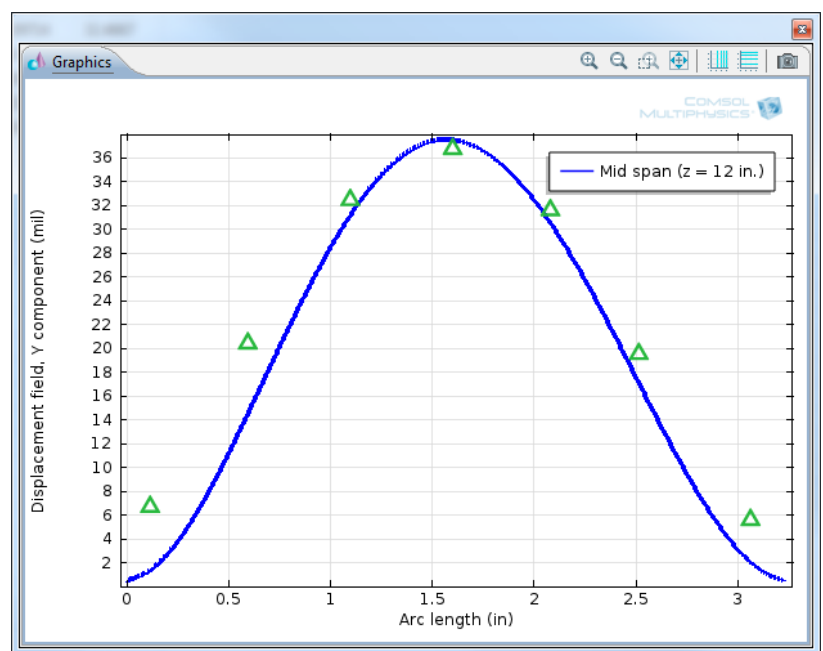

(a)

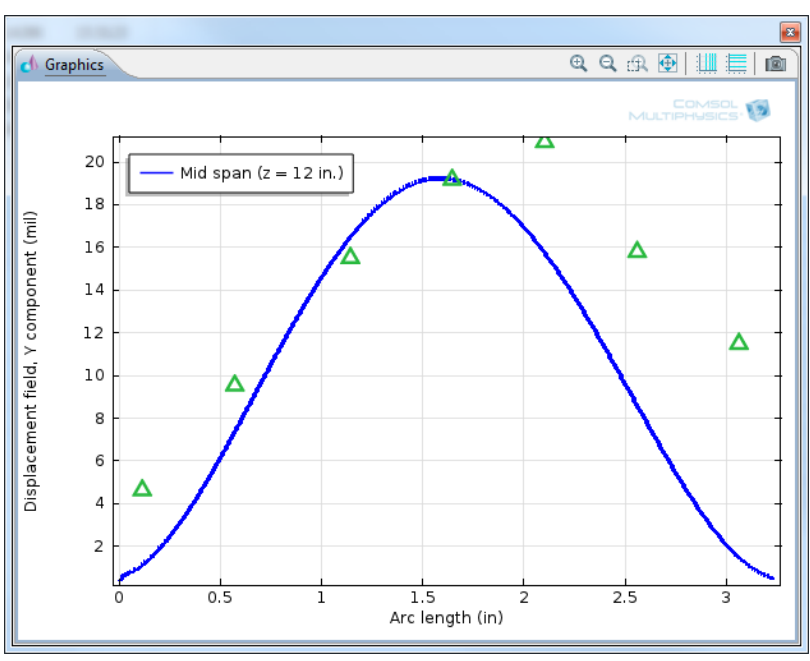

(b)

Fig. 25. Comparison of mid-span deflections of an aluminum plate attached with Invar (a) solid and (b) split bases with experimental results in Fig. 8. Detailed results for these simulation cases are shown in Figs. 21 and 22 . 


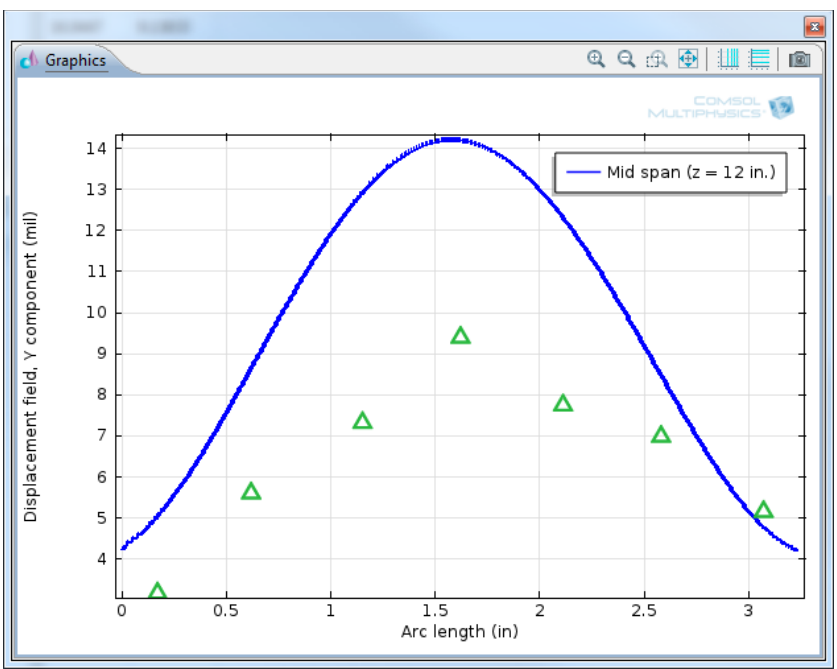

(a)

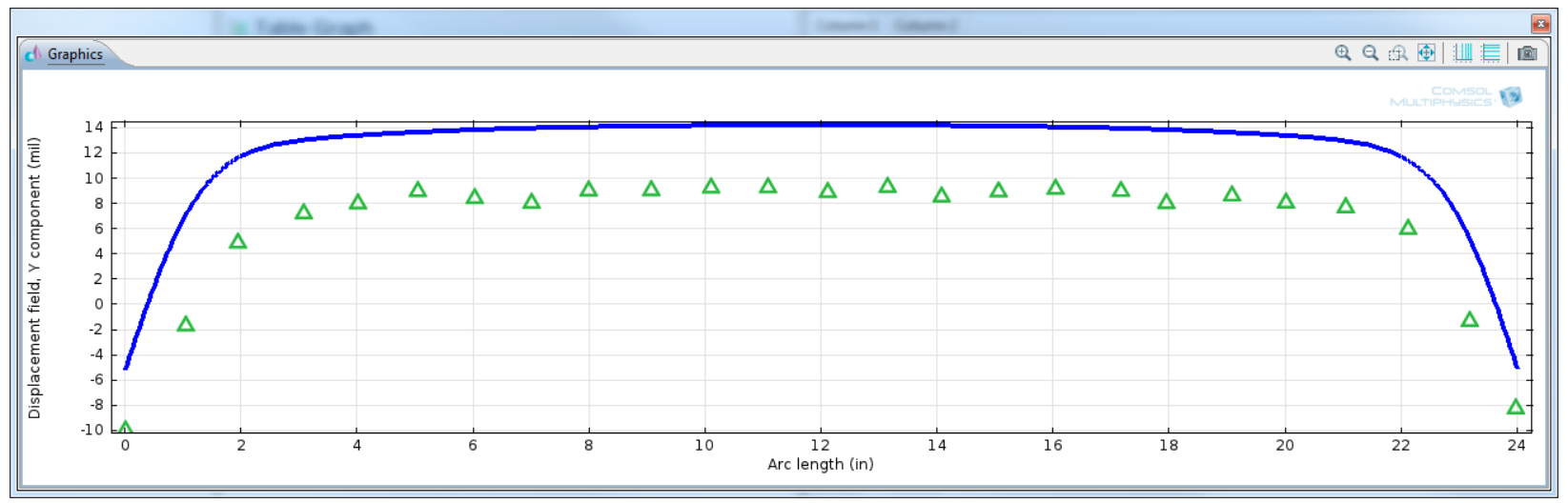

(b)

Fig. 26. Comparison of mid-span and longitudinal deflections of an aluminum plate attached with split steel base with experimental results in Fig. 7. Detailed results for the simulation is shown in Fig. 20. 
Table 3. Comparison of peak deformations at the longitudinal midspan and top/bottom ends of the plate with experimental data

\begin{tabular}{|c|c|c|c|c|c|}
\hline $\begin{array}{l}\text { Plate-base } \\
\text { combination }\end{array}$ & Plate type & Base type & Location & $\begin{array}{l}\text { Experimental } \\
\text { peak deformation } \\
\text { (mil) }\end{array}$ & $\begin{array}{l}\text { Simulated peak } \\
\text { deformation } \\
\text { (mil) }\end{array}$ \\
\hline \multirow[t]{4}{*}{ Al-Steel } & Regular & Solid & Midspan ( $\mathrm{z}=12$ in.) & $\mathrm{n} / \mathrm{a}$ & 25 \\
\hline & & & Ends $(z=0$ or 24 in.) & $\mathrm{n} / \mathrm{a}$ & 13 \\
\hline & & Split & Midspan & 12.5 & 14.2 \\
\hline & & & Ends & -10.5 & -6.3 \\
\hline \multirow[t]{4}{*}{ Al-Invar } & Regular & Solid & Midspan & 37 & 39.6 \\
\hline & & & Ends & 7 & 16 \\
\hline & & Split & Midspan & 17.5 & 19.2 \\
\hline & & & Ends & -18 & -23 \\
\hline \multirow[t]{4}{*}{ Al-Invar } & Cold ended & Solid & Midspan & $\mathrm{n} / \mathrm{a}$ & 40.6 \\
\hline & & & Ends & $\mathrm{n} / \mathrm{a}$ & 7.5 \\
\hline & & Split & Midspan & 26.5 & 19.7 \\
\hline & & & Ends & -16.5 & -27.6 \\
\hline
\end{tabular}

The following qualitative behavior, as observed in the experiments, is also apparent from the simulation results:

- For a plate attached to a solid base, the whole plate tends to deflect toward the convex of the involute when heated and has a uniform deflection in the longitudinal central portion of the plate except for its ends, where the deflections are relatively minor.

- For a plate attached to a split base, the top and bottom ends tend to deflect in an opposite direction from the rest of the plate (negative deflection).

- Because their differential thermal expansion is lower than that for aluminum plate, cold steel ends tend to have a restraining effect and as a result, yield significantly lower end deformations for the solid base and about the same maximum deformation for the rest of the plate.

The above qualitative and quantitative comparisons show that the COMSOL simulations are able to capture the physical reality within engineering limits and therefore could be applied for predictive calculations in determining thermal expansion behavior of HFIR fuel plates. 


\section{CONCLUSIONS}

In 1968, Cheverton and Kelley designed an experimental setup to investigate temperature- and pressureinduced deflections of HFIR's outer fuel plate. The study was performed with the intention of determining whether the HFIR fuel plate would buckle at the steady-state reactor operating conditions and to estimate temperature- and pressure-induced deflection magnitude and profile for the HFIR plate to be included in the SSHTC code. The experiment was a greatly simplified representation of the HFIR's steady-state conditions with uniform convective heating, cold (steel) ends, controlled pressure deflections at the surfaces, and a split base to mimic rotatable side plates; however, it was able to identify some key qualitative features very accurately (e.g., thermal-expansion-induced deflection profiles in the radial and longitudinal directions and the absence of buckling even when heating the plate to a higher-than-normal temperature.)

Simulation results in Sect. 5 and their good agreement with experimental data (both qualitative and quantitative) confirm that the finite-element-method-based 3D COMSOL simulations are able to accurately predict these structural behaviors, precluding the need for repeating Cheverton-Kelley tests for the LEU plates. Furthermore, COMSOL simulations will be able to provide detailed assessments of more realistic scenarios - with better predictive capability than the Cheverton-Kelley experiments for the HFIR core - using turbulent flow, conjugate heat transfer physics, and structural mechanics. 


\section{REFERENCES}

1. Office of Global Threat Reduction. Web link: http://nnsa.energy.gov/gtri, last accessed on 03/14/2012.

2. Reduced Enrichment for Research and Test Reactors. Web link: http://www.rertr.anl.gov/, last accessed on 03/14/2012.

3. J. Rest, Y. S. Kim, G. L. Hofman, M. K. Meyer, and S. L. Hayes, U-Mo Fuels Handbook - Version 1.0, Technical Report, RERTR Program, Argonne National Laboratory, USA, 2006.

4. D. E. Burkes, G. S. Mickum, and D. M. Wachs, Thermo-physical Properties of U-10Mo Alloy, Technical Report, INL/EXT-10-19373, Idaho National Laboratory, 2010.

5. J. G. Stevens, "Technical Challenges for Conversion of U.S. High Performance Research Reactors," Presentation to NAS/RAS committee on conversion of research reactors, available at:

http://dels.nas.edu/resources/static-assets/nrsb/miscellaneous/StevensPresentation.pdf, 2010.

6. L. Tschape, A. E. Ruggles, J. D. Freels, and R. T. Primm III, Evaluation of HFIR LEU Fuel using the COMSOL Multiphysics Platform, ORNL/TM-2008/188, Oak Ridge National Laboratory, 2009.

7. J. D. Freels, R. V. Arimilli, K. T. Lowe, and I. T. Bodey, "The Role of COMSOL towards a Low Enriched Uranium Fuel Design for the High Flux Isotope Reactor," Proc. COMSOL Conference 2009, Boston, Mass., October 8-10, 2009 (2009).

8. I. T. Bodey, R. V. Arimilli, and J.D. Freels, "Upgrading the HFIR Thermal-Hydraulic Legacy Code using COMSOL,” Proc. COMSOL Conference 2010, Boston, Mass., October 7-9, 2010 (2010).

9. J. D. Freels, R. V. Arimilli, and I. T. Bodey, "Exploiting New Features of COMSOL Version 4 on Conjugate Heat Transfer Problems," Proc. COMSOL Conference 2010, Boston, Mass., October 7-9, 2010 (2010).

10. J. D. Freels, I. T. Bodey, R. V. Arimilli, and K. T. Lowe, Two-Dimensional Thermal Hydraulic Analysis and Benchmark in Support of HFIR LEU Conversion using COMSOL, ORNL/TM-2010/18, Oak Ridge National Laboratory, 2010.

11. G. Ilas and R. T. Primm III, Fuel Grading Study on a Low-Enriched Fuel Design for the High Flux Isotope Reactor, ORNL/TM-2009/223/R1, Oak Ridge National Laboratory, 2010.

12. R. T. Primm III, D. Chandler, J. D. Feels, T. Guida, G. Ilas, B. C. Jolly, J. H. Miller, and J.D. Sease, Design Study for a Low-Enriched Uranium Core for the High Flux Isotope Reactor, ORNL/TM2009/313, Oak Ridge National Laboratory, 2010.

13. P. K. Jain, J. D. Freels, and D. H. Cook, "COMSOL-based Multiphysics Simulations to Support HFIR's Conversion to LEU Fuel,” Trans. Amer. Nucl. Soc. 104:1064-1066, 2011.

14. J.D. Freels and P.K. Jain, "Multiphysics Simulations in the Complex 3D Geometry of the High Flux Isotope Reactor Fuel Elements Using COMSOL," COMSOL Conference, Newton, Mass, October 13-15, 2011. 
15. J. D. Freels, I. T. Bodey, R. V. Arimilli, F. G. Curtis, K. Ekici, and P. K. Jain, Preliminary Multiphysics Analyses of HFIR LEU Fuel Conversion using COMSOL, ORNL/TM-2011/07, Oak Ridge National Laboratory, 2011.

16. R. T. Primm III, D. H. Cook, J. D. Feels, G. Ilas, B. C. Jolly, J. H. Miller, D. L. Pinkston, D. G. Renfro, and J. D. Sease, Design Study for a Low-Enriched Uranium Core for the High Flux Isotope Reactor, ORNL/TM-2011/06, Oak Ridge National Laboratory, 2011.

17. H. A. McLain, HFIR Fuel Element Steady State Heat Transfer Analysis-Revised Version, ORNLTM-1904, Oak Ridge National Laboratory, 1967.

18. COMSOL Multiphysics Simulation Software. Web link: http://www.comsol.com/, last accessed on 03/14/2012.

19. R. D. Cheverton and W. H. Kelley, Experimental Investigation of HFIR Fuel Plate Deflections Induced by Temperature and Pressure Differentials, ORNL-TM-2325, Oak Ridge National Laboratory, 1968.

20. R. B. Rothrock, Thermal-Hydraulic Bases for the Safety Limits and Limiting Safety System Settings for HFIR Operation at $100 \mathrm{MW}$ and 468 psig Primary Pressure, Using Specially Selected Fuel Elements, ORNL/TM-13694, Oak Ridge National Laboratory, 1998. 
ORNL/TM-2012/138

\section{INTERNAL DISTRIBUTION}

1. J. L. Binder (binderj1@ornl.gov)

2. K. J. Beierschmitt (beierschmitt@ornl.gov)

3. S. J. Zinkle (zinklesj@ornl.gov)

4. C. V. Parks (parkscv@ornl.gov)

5. R. A. Crone (cronera@ ornl.gov)

6. D. G. Renfro (renfrodg@ornl.gov)

7. D. B. Kothe (kothe@ornl.gov)

8. J. C. Wagner (wagnerjc@ornl.gov)

9. G. L. Yoder, Jr. (yodergljr@ornl.gov)

10. J. C. Gehin (gehinjc@ ornl.gov)

11. K. A. Smith (smithka@ornl.gov)

12. J. A. Turner (turnerja@ornl.gov)

13. J. J. Carbajo (carbajojj@ornl.gov)

14. E. L. Popov (popove@ornl.gov)

15. G. Ilas (ilasg@ornl.gov)

16. J. D. Sease (seasejd@ornl.gov)
17. F. P. Griffin (griffinfp@ornl.gov)

18. J. R. Valentine (valentinejr@ornl.gov)

19. D. Chandler (chandlerd@ornl.gov)

20. I. T. Bodey (bodeyit@ornl.gov)

21. F. G. Curtis (curtisfg@ornl.gov)

22. K. T. Clarno (clarnokt@ornl.gov)

23. C. R. Hyman III (hymancriii@ornl.gov)

24. J. H. Miller (millerjh2 @ornl.gov)

25. G. I. Bell (bellgi@ornl.gov)

26. S. M. Bowman (bowmansm2ornl.gov)

27. S. E. Burnette (burnettese@ornl.gov)

28. A. S. Icenhour (icenhouras@ornl.gov)

29. D. L. Pinkston (pinkstondl@ornl.gov)

30. L. J. Satkowiak (satkowiaklj@ ornl.gov)

31. W. J. Toth (tothwj@ornl.gov)

32. ORNL Laboratory Records (hamrindr@ornl.gov)

\section{EXTERNAL DISTRIBUTION}

33. R. V. Arimilli, University of Tennessee at Knoxville (arimilli@utk.edu)

34. K. Ekici, University of Tennessee at Knoxville (ekici@utk.edu)

35. A. Adams, U.S. Nuclear Regulatory Commission, One White Flint North, 11555 Rockville Pike, Rockville, Maryland 20852-2738 (axa@nrc.gov)

36. R. A. Butler, Director, Research Reactor Center, 1513 Research Park Drive, Columbia, MO 65211 (ButlerRa@missouri.edu)

37. G. S. Chang, Idaho National Laboratory, P.O. Box 1625, Idaho Falls, ID 83415-3885 (gray.chang@inl.gov)

38. J. Chamberlin, NA-212, U.S. Department of Energy, 1000 Independence Avenue SW, Washington, DC 20585 (jeffry.chamberlin@nnsa.doe.gov)

39. D. Diamond, Brookhaven National Laboratory, P.O. Box 5000, Upton, NY 11973-5000 (diamond@bnl.gov)

40. D. Kutikkad, Assistant Reactor Manager-Physics, University of Missouri Research Reactor Facility, Columbia, MO 65211 (kutikkadk@missouri.edu)

41. C. Landers, NA-212, U.S. Department of Energy, 1000 Independence Avenue SW, Washington, DC 20585 (Christopher.landers@ nnsa.doe.gov)

42. J. Matos, Argonne National Laboratory, 9700 S. Cass Avenue, Argonne, IL 60439 (jim.matos@anl.gov)

43. C. McKibben, University of Missouri Research Reactor Facility, Columbia, MO 65211 (mckibbenj@missouri.edu)

44. J. Dwight, Idaho National Laboratory, P.O. Box 1625, Idaho Falls, ID 83415-3750 (John.Dwight@inl.gov)

45. T. Newton, MIT Nuclear Reactor Laboratory, 138 Albany St., Cambridge, MA 02139 (tnewton@mit.edu)

46. W. Richards, NIST Center for Neutron Research, 100 Bureau Drive, Stop 8561, Gaithersburg, MD 20899-8561 (wade.richards@ nist.gov)

47. J. Roglans, Argonne National Laboratory, 9700 S. Cass Avenue, Argonne, IL 60439 (roglans@anl.gov) 
48. P. Roth, Idaho National Laboratory, P.O. Box 6188, Idaho Falls, ID 83415 (Paul.Roth@inl.gov)

49. P. Staples, NA-212, U.S. Department of Energy, 1000 Independence Avenue SW, Washington, DC 20585 (Parrish.Staples@nnsa.doe.gov)

50. J. G. Stevens, Argonne National Laboratory, 9700 S. Cass Avenue, Argonne, IL 60439 (johnstevens@anl.gov)

51. D. M. Wachs, MFC 791 B-147, Idaho National Laboratory, P.O. Box 6188, Idaho Falls, ID 83415 (Daniel.Wachs@inl.gov)

52. R. E. Williams, NIST Center for Neutron Research, 100 Bureau Drive, Stop 8560, Gaithersburg, MD 20899-8560 (robert.williams@ nist.gov)

53. S. O'Kelly, NIST Center for Neutron Research, 100 Bureau Drive, Stop 8560, Gaithersburg, MD 20899-8560 (sean.okelly@ nist.gov)

54. W. C. Richardson, Babcock \& Wilcox Nuclear Operations Group, 2016 Mount Athos Rd., Lynchburg, VA 24504 (WCRichardson@bwxt.com)

55. E. C Woolstenhulme, P.O. Box 1625, Idaho Falls, ID 83415-3750 (Eric.Woolstenhulme@inl.gov)

56. Peter Lee, Office of Basic Energy Sciences, U.S. Department of Energy, 1000 Independence Avenue SW, Washington, DC 20585 (peter.lee@science.doe.gov)

57. C. Sohn, Office of Basic Energy Sciences, U.S. Department of Energy, 1000 Independence Avenue SW, Washington, DC 20585 (carol.sohn@pnso.science.doe.gov)

58. J. O. Moore, U.S. Department of Energy (moorejo@ornl.gov)

59. L. Foyto, Research Reactor Center, 1513 Research Park Drive, Columbia, MO 65211 (foytol@missouri.edu)

60. L. Jollay, Y-12 National Security Complex (jollayl@y12.doe.gov)

61. D. Rosine, U.S. Department of Energy (rosinedb@ornl.gov)

62. D. Reed, U.S. Department of Energy (reeddr@ornl.gov)

63. G. Solbrekken, University of Missouri, Columbia, MO 65211 (solbrekkeng@ missouri.edu)

64. D. McDaniel, Idaho National Laboratory, P.O. Box 6188, Idaho Falls, ID 83415 (David.McDaniel@inl.gov)

65. Hollie Longmire, Y-12 National Security Complex (longmireha@y12.doe.gov)

66. Jared M. Wight, Babcock \& Wilcox Nuclear Operations Group, 2016 Mount Athos Rd., Lynchburg, VA 24504 (jmwight@babcock.com)

67. Mitch Meyer, P.O. Box 1625, Idaho Falls, ID 83415-3750 (Mitchell.Meyer@inl.gov)

68. Anthony Vinnola, P.O. Box 1625, Idaho Falls, ID 83415-3750 (Anthony.vinnola@inl.gov)

69. Ann Marie Phillips, P.O. Box 1625, Idaho Falls, ID 83415-3750 (AnnMarie.Phillips@inl.gov)

70. Wade Marcum, Oregon State University (marcumw@engr.orst.edu)

71. Joe Cleary, Pacific Northwest National Laboratory (joe.cleary@pnl.gov)

72. MaryJane Ross-Lee, U.S. Nuclear Regulatory Commission (maryjane.ross-lee@ nrc.gov)

73. Harriet Kung, Office of Basic Energy Sciences, U.S. Department of Energy, 1000 Independence Avenue SW, Washington, DC 20585 (harriet.kung@science.doe.gov)

74. Van T. Nguyen, Office of Basic Energy Sciences, U.S. Department of Energy, 1000 Independence Avenue SW, Washington, DC 20585 (van.nguyen@science.doe.gov)

75. Kenneth B. Sheely, NA-21, U.S. Department of Energy, 1000 Independence Avenue SW, Washington, DC 20585 (ken.sheely@ @q.doe.gov)

76. Michele G. Branton, U.S. Department of Energy (brantonmg@ornl.gov)

77. H. Randall Persinger, U.S. Department of Energy (persingerhr@ornl.gov)

78. Douglas Burkes, Pacific Northwest National Laboratory (douglas.burkes@nnsa.doe.gov)

79. Aurelien Bergeron, Argonne National Laboratory (abergeron@anl.gov)

80. Adrien Tentner, Argonne National Laboratory (tentner@anl.gov) 